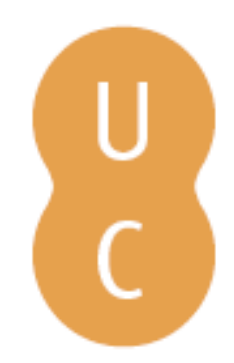

\title{
pommalina
}

\section{Macedonia (Fyron): collectanea ex operis auctorum romanorum ad Macedoniam pertinentia}

\author{
Autor(es): Dimovska, Vesna \\ Publicado por: Imprensa da Universidade de Coimbra \\ URL \\ persistente: URI:http://hdl.handle.net/10316.2/38411 \\ DOI: $\quad$ DOI:http://dx.doi.org/10.14195/978-989-26-0670-5_10 \\ Accessed : $\quad$ 26-Apr-2023 14:17:43
}

A navegação consulta e descarregamento dos títulos inseridos nas Bibliotecas Digitais UC Digitalis, UC Pombalina e UC Impactum, pressupõem a aceitação plena e sem reservas dos Termos e Condições de Uso destas Bibliotecas Digitais, disponíveis em https://digitalis.uc.pt/pt-pt/termos.

Conforme exposto nos referidos Termos e Condições de Uso, o descarregamento de títulos de acesso restrito requer uma licença válida de autorização devendo o utilizador aceder ao(s) documento(s) a partir de um endereço de IP da instituição detentora da supramencionada licença.

Ao utilizador é apenas permitido o descarregamento para uso pessoal, pelo que o emprego do(s) título(s) descarregado(s) para outro fim, designadamente comercial, carece de autorização do respetivo autor ou editor da obra.

Na medida em que todas as obras da UC Digitalis se encontram protegidas pelo Código do Direito de Autor e Direitos Conexos e demais legislação aplicável, toda a cópia, parcial ou total, deste documento, nos casos em que é legalmente admitida, deverá conter ou fazer-se acompanhar por este aviso.

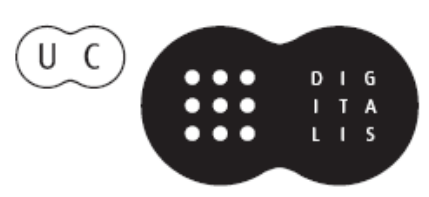


Vesna Dimovska - Ss Cyril and Methodius University, Skopje

Email: vesna.dimovska@gmail.com

\author{
MACEDON I A ( F Y ROM )
}

\title{
COLLECTANEA EX OPERISAUCTORUM ROMANORUM A D MACEDONIAM PERTINENTIA
}

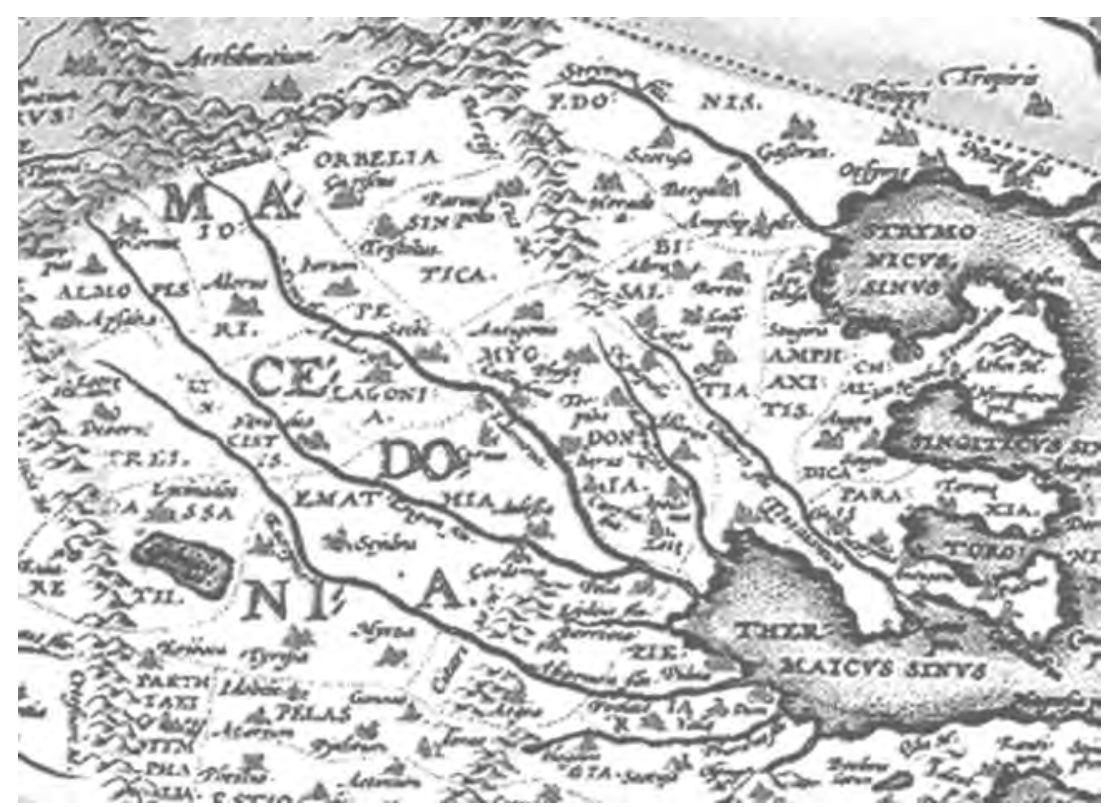

collegit Polemocles D. f. Scupensis Scupis, Kal. Dec. MMDCCLX a.U.c.

Quam ob rem aequales nostri linguam Latinam evitent? Ita fit hodie, ut haud quisquam reperiri possit, qui de lingua Latina seria mente meditatur. Etiamsi causam iustiorem esse negamus, tempora et mores hodiernas criminati, est nobis tamen cogitandum et solutionem, ut medelam, ad statum corrigere quaerendum. 
Magna pars hominum non philologi sunt; de historia quidem antiqua perpauca sciunt. Tamen, linguae Latinae amatores invenire possumus, qui aut olim Latine docebantur, aut nunc in scholis docentur. Iuvat igitur, et maxime necesse est, de Romanis, de lingua eorum, de sententiis etiam Latinis aliisque rebus cum hominibus colloqui. Quo consilio? Philologorum porro est homines linguae culturaeque Romanae conciliare; ac si quis libros, fontes, codices, auxilium quidquid petiverit, eum benevole iuvare. A plebe haud recedendum est; immo, lingua Latina inter homines diligenter propaganda.

His rebus adducti, et non sine invidia spectantes quanta acie animi, quantaque sagacitate, ut propositum erat, amici nostri collecta ad Europatriam finierunt, ad faciendum idem curavimus et collectanea ad Macedoniam antiquam pertinentia collegimus. Negotium haud facile. In scriptoribus Romanis aestimandis duas semper res inter se distingui oportebat, quatenus de litteris Romanis bene meriti sint et quanti ipsi homines aestimandi. Nunc nobis distinctio tertia facienda erat - quatenus opera eorum ad Macedoniam antiquam pertinent et quomodo. Diu multumque cogitantes, opera T. Livi, Q. Curtii Rufi Cornelii Nepotisque pro tempore seiungere constituimus; nam dubium non esse videtur, quin operis eorum inclusis non libellum, sed tomum pergrandem prodiderimus.

Res, de qua disserimus, magni nobis momenti esse videtur: putamus - dis volentibus - omnes linguae Latinae adversantes, libellum nostrum percursos, admittere se peccare; idem, collectanea nostra non solum philologis et historicis, sed etiam omnibus linguae Latinae amatoribus patere putamus, dummodo ad Latine lectum parati sint.

Speramus, demum, mox etiam in interreti locum esse, ubi omnia collectanea colligere possimus, ut quo facilius, qui quaerunt excerpta auctorum antiquorum ad nationes hodiernas pertinentes, ea inveniant, potissimum ligaminibus interiuncta.

Salvete omnes, bonoque animo este.

Scupis, Kal. Dec. MMDCCLX a.U.c. 
CONSPECTVS

1. Haec est Macedonia, terrarum imperio potita quondam

2. Macedonum origines, nondum Romanis auctoribus celebratae

3. Fortissimi dei Martis clientes

4. Varia Macedonum strategemata

5. Quid inter Indos, Persas Aegyptiosque Macedonicus sermo?

6. Macedonum memorabilia

7. Pauca de artibus

8. Macedonum cum Romanis contentio

9. Provincia non turribus, sed tropaeis munita

10. Caesares Augusti Macedones adsimulant

\section{Haec est Macedonia, terrarum imperio potita quondam}

Mare quod primo sinu accipit Aegaeum dicitur; quod sequenti in ore Ionium, Hadriaticum interius; quod ultimo nos Tuscum [quem] Grai Tyrrbenicum perbibent. gentium prima est Scythia, alia quam dicta est ad Tanain, media ferme Pontici lateris, hinc in Aegaei partem pertinens Thracia, huic Macedonia adiungitur. tum Graecia prominet, Aegaeumque ab Ionio mari dirimit. Hadriatici latus Illyris occupat. Inter ipsum Hadriaticum et Tuscum Italia procurrit.

(Pomponii Melae De Chorographia 1. 17-19)

Clarissimi montes in orbe terrarum: Caucasus in Scythia, Emodus in India, Libanus in Syria, Olympus in Macedonia, Hymettus in Attica, Taygetus Lacedaemonia, Cithaeron et Helicon in Boetia, Parnasos [et] <in Phocide, > Acroceraunia in Epiro, Maenalus in Arcadia, Apenninus in Italia, Eryx in Sicilia, Alpes inter Galliam <et Italiam>, Pyrenaeus inter Galliam et Spaniam, Athlans in Africa, Calpe in freto Oceani.

(Lucii Ampelii Liber Memorialis 6. 7)

'Musae quae pedibus magnum pulsatis Olympum'. caelum dicunt Graeci Olympum, montem in Macedonia omnes; a quo potius puto musas 
dictas Olympiadas: ita enim ab terrestribus locis aliis cognominatae Libethrides, Pipleides, <T>hespiades, <H>eliconides.

(M. Terrentii Varronis De lingua Latina 7. 20)

In Olympo Macedoniae monte non sunt lupi nec in Creta insula; ibi quidem nec ulpes ursive atque omnino nullum maleficum animal praeter phalangium.

(C. Plinii Secundi Naturalis Historia 8. 227)

Macedonia postea CL populorum, duobus incluta regibus quondamque terrarum imperio, Emathia antea dicta. haec ad Epiroticas gentes in solis occasum recedens post terga Magnesiae atque Thessaliae infestatur a Dardanis; partem eius septentrionalem Paeonia ac Pelagonia protegunt a Triballis. oppida Aegae, in quo sepeliri mos reges, Beroea et in regione, quae Pieria appellatur a nemore, Aegi<n>ium. in ora Heraclea, flumen Apilas, oppida Py<d $>n a,<A>$ loros, amnis Haliacmon. intus Aloritae, Vallaei, Phylacaei, Cyrrestae, Tyrissaei, Pella colonia, oppidum Stobi civium Romanorum, mox Antigonea, Europus ad Axium amnem, eodemque nomine per quod Rhoedias fluit, Scydra, $<E>$ ordaea, Mi<e>za, Gordyniae. mox in ora Ichnae, fluvius Axius, ad hunc finem Dardani, Treres, Pieres Macedoniam accolunt. ab hoc amne Paeoniae gentes Para<xi>aei, Eordenses, Almopi, Pelagones, Mygdones. montes Rhodope, Scopius, Orbelus. dein praeiacente gremio terrarum Arethusii, Antiochienses, Idomenenses, Doberi, $<$ A>estrienses, Allantenses, Audaristenses, Morylli, Garresci, Lyncestae, Othryonei et liberi $<$ A mantini atque Orestae, coloniae Bullidenses et Dienses, Xylopolitae, Scotusaei liberi, Heraclea Sintica, Tymphaei, Toronaei.

In ora sinus Macedonica oppidum Chalastra et intus Piloros, Lete medioque litoris flexu Thessalonice liberae condicionis - ad hanc a Dyrrbachio CCXLV-, Therme in Thermaico sinu, oppida Dicaea, Palinandrea, Scione, promunturium Canastraeum, oppida Pallene, Phlegra. qua in regione montes Hypsizo<n>us, Epytus, Alcyon, Elaeuomne, oppida Nissos, Phryxelon, Mendae et in Pallenensi Isthmo quondam Potidaea, nunc 
Cassandrea colonia, Anthemus, Olop<b>yxus, sinus Mecyberna, oppida Myscella, Ampelos, Torone, Siggos, $<S>t<0>l o s$, fretum, quo montem Atho Xerxes Persarum rex continenti abscidit in longitudinem passuum MD. mons ipse a planitie excurrit in maria LXXV passuum, ambitus radicis $C L$ colligit. oppidum in cacumine fuit Acrotho $<0>n$; nunc sunt Vranopolis, Pal<a>ehorium, Thy<s $>$ sus, Cleonae, Apollonia, cuius incolae Macrobii cognominantur. oppidum Cassera faucesque alterae Isthmi, Acanthus, Stagira, Sithone, Heraclea et regio Mygdoniae subiacens, in qua recedentes a mari Apollonia, Arethusa. in ora rursus Posidium et sinus cum oppido Cermoro, Amphipolis liberum, gens Bisaltae. dein Macedoniae terminus amnis Strymon, ortus in Haemo. memorandum in septem lacus eum fundi, priusquam derigat cursum.

(C. Plinii Secundi Naturalis Historia 4. 33-38)

Circa Hebrum Cicones, trans eundem Doriscos, ubi Xerxen copias suas quia numero non poterat spatio mensum ferunt. dein promunturium Serrbion, et quo canentem Orphea secuta narrantur etiam nemora Zone. tum Sthenos fluvius, et ripis eius adiacens Maronia. regio ulterior Diomeden tulit, inmanibus equis mandendos solitum obiectare advenas et iisdem ab Hercule obiectum. turris quam Diomedis vocant signum fabulae remanet, et urbs quam soror eius suo nomine nominavit Abdere; sed ea magis id memorandum habet, quod Democritum physicum tulit, quam quod ita condita est. ultra Nestos fluit, interque eum et Strymona urbes sunt Philippi, Apollonia, Amphipolis; inter Strymona et Athon turris Calarnaea et portus Capru limen, urbs Acanthos et Echinia; inter Athon et Pallenen Cleona et Olynthos. Strymon, sicut diximus, amnis est longeque ortus et tenuis. alienis subinde aquis fit amplior, et ubi non longe a mari lacum fecit, maiore quam venerat alveo erumpit. Atho mons adeo altus est, ut credatur altius etiam quam unde imbres cadunt surgere. capit opinio fidem, quia de aris quas in vertice sustinet non abluitur cinis, sed quo relinquitur aggere manet. ceterum non promunturio ut alii, verum totus et toto longoque dorso procedit in pelagus. qua continenti adhaeret a Xerxe in Graios tendente perfossus transnavigatusque 
est - adbuc freto navigabili pervius. ima eius tenent parvae Pelasgorum coloniae. in summo fuit oppidum Acrothoon, in quo, ut ferunt, dimidio longior quam in aliis terris aetas habitantium erat. Pallene soli tam patentis, ut quinque urbium sedes sit atque ager, tota in altum abit, angusta satis unde incipit. ibi est Potidaea, at ubi latius patet, Mende Scioneque referendae, illa ab Eretriis, haec ab Achivis capto Ilio remeantibus posita.

Tum Macedonum populi <ali>quot urbes habitant, quarum Pelle est maxime inlustris. alumni efficiunt, Philippus Graeciae domitor, Alexander etiam Asiae. in litore flexus Megybernaeus, inter promunturia Derim et Canastraeum et portum qui Cophos dicitur urbes Toronen et Myscellam atque unde ipsi nomen est Megybernam incingit. Canastraeo promunturio Sane proxima est, Megybernaeus in medio, qua terra dat gremium, modice in litora ingreditur. ceterum longis et in altum inmissis lateribus ingens inde Thermaicus sinus est. in eum Axius per Macedonas, et iam per Thessalos Peneus excurrit. ante Axium Thessalonice est, inter utrumque Cassandria, Cydna, Aloros, Itharis. a Peneo ad Sepiada Corynthya, Meliboea, Castanaea pares ad famam nisi quod Philoctetes alumnus Meliboean inluminat. terrae interiores claris locorum nominibus insignes paene nibil ignobile ferunt. hinc non longe est Olympus, bic Pelion hic Ossa, montes gigantum fabula belloque memorati; hic Musarum parens domusque Pieria; bic novissime calcatum Graio Herculi solum, saltus Oetaeus; hic sacro nemore nobilia Tempe; hic Libethra carminum fontes.

(Pomponii Melae De Chorographia 2. 28-37)

In Macedonia quoque, ut ait Theophrastus, qui facere albas oues uolunt, <ad Haliacmonem> adducunt; quem ut diutius potauere, non aliter quam infectae mutantur. At si illis lana opus fuit pulla, paratus gratuitus infector est: ad Peneion eundem gregem appellunt. Auctores bonos habeo esse in Galatia flumen quod idem in omnibus efficiat, esse in Cappadocia quo poto equis, nec ulli praeterea animali, color mutetur et spargatur albo cutis.

(L. Annaei Senecae Iunioris Naturales quaestiones 3. 25.4) 
Eudicus in Hestiaeotide fontes duos tradit esse, Ceronam, ex quo bibentes oves nigras fieri, <N>elea, ex quo albas, ex utroque varias, Theophrastus Thuriis Crathim candorem facere, Sybarim nigritiam bubus ac pecori, quin et homines sentire differentiam eam; nam qui e Sybari bibant, nigriores esse durioresque et crispo capillo, qui e Crathi candidos $m<$ oll $>$ ioresque ac porrecta coma. item in Macedonia qui velint sibi candida nasci, ad Haliacmonem ducere, qui nigra aut fusca, ad Axium. idem omnia fusca nasci quibusdam in locis dicit et fruges quoque, sicut in Messapis, at in Lusis Arcadiae quodam fonte mures terrestres vivere et conversari. Erythris Aleos amnis pilos gignit in corporibus.

(C. Plinii Secundi Naturalis Historia 31. 13-14)

Etiamque inveniuntur aquae genera mortifera, quae per maleficum sucum terrae percurrentia recipiunt in se vim venenatam, uti fuisse dicitur Terracinae fons, qui vocabatur Neptunius, ex quo qui biberant inprudentes, vita privabantur; quapropter antiqui eum obstruxisse dicuntur. et Chrobsi Thracia lacus, ex quo non solum qui biberint, moriuntur, sed etiam qui laverint. item in Thessalia fons est profluens, ex quo fonte nec pecus ullum gustat nec bestiarum genus ullum propius accedit; ad quem fontem proxime est arbor florens purpureo colore. non minus in Macedonia quo loci sepultus est Euripides, dextra ac sinistra monumenti advenientes duo rivi concurrunt in unum, e quibus ad unum accumbentes viatores pransitare solent propter aquae bonitatem, ad rivum autem, qui est ex altera parte monumenti, nemo accedit, quod mortiferam aquam dicitur habere.

(Vitruvii Pollionis De Architectura 8. 3.15)

Haec est Macedonia terrarum imperio potita quondam, haec Asiam, Armeniam, Hiberiam, Albaniam, Cappadociam, Syriam, Aegyptum, Taurum, Caucasum transgressa, haec in Bactris, Medis, Persis dominata toto oriente possesso, haec etiam Indiae victrix per vestigia Liberi 
Patris atque Herculis vagata. haec eadem est Macedonia, cuius uno die Paulus Aemilius imperator noster LXXII urbes direptas vendidit. tantam differentiam sortis praestitere duo bomines!

(C. Plinii Secundi Naturalis Historia 4. 39)
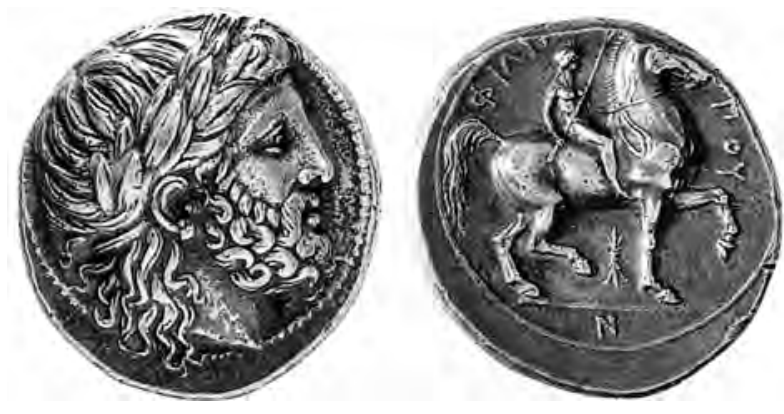

\section{Macedonum origines, nondum Romanis auctoribus celebratae}

Atque illud etiam scriptum fuit, quae nomina fuerint sociorum

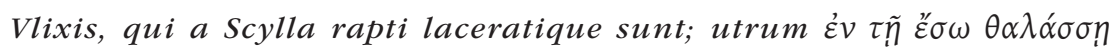

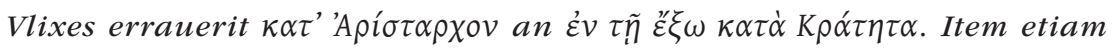
istic scriptum fuit, qui sint apud Homerum uersus isopsephi; et quorum ibi nominum $\pi \alpha \rho \alpha \sigma \tau \imath \chi i ́ \varsigma$ reperiatur; et quis adeo uersus sit, qui per singula uocabula singulis syllabis increscat; ac deinde qua ratione dixerit singulas pecudes in singulos annos terna parere; et ex quinque operimentis, quibus Achillis clipeus munitus est, quod factum ex auro est, summum sit an medium; et praeterea quibus urbibus regionibusque uocabula iam mutata sint, quod Boeotia ante appellata fuerit 'Aonia', quod Aegyptus 'Aeria', quod Creta quoque eodem nomine 'Aeria' dicta

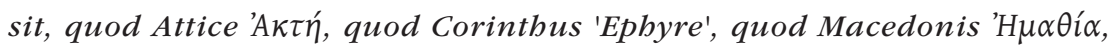
quod Thessalia Aipovíx, quod Tyros 'Sarra', quod Thracia ante 'Sithonia'

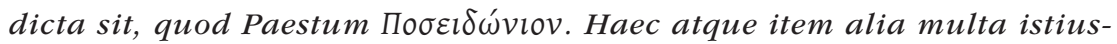
modi scripta in eo libro fuerunt.

(Auli Gellii Noctes Atticae 14. 6. 3-5) 
Lyra inter sidera constituta est hac, ut Eratosthenes ait, de causa, quod initio a Mercurio facta de testudine, Orpheo est tradita, qui, Calliopes et Oeagri filius, eius rei maxime studiosus fuit. Itaque existimatur suo artificio feras etiam ad se audiendum adlicuisse. Qui querens uxoris Eurydices mortem, ad inferos descendisse existimatur, et ibi deorum progeniem suo carmine laudasse, praeter Liberum patrem; bunc enim obliuione ductus praetermisit, ut Oeneus in sacrificio Dianam. Postea igitur Orpheus, ut complures dixerunt, in Olympo monte, qui Macedoniam diuidit a Thracia, sed ut Eratosthenes ait, in Pangaeo sedens, cum cantu delectaretur, dicitur ei Liber obiecisse Bacchas, quae corpus eius discerperent interfecti. Sed alii dicunt, quod initia Liberi sit speculatus, id ei accidisse. Musas autem collecta membra sepulturae mandasse, et lyram, quo maxime potuerant beneficio, illius memoriae causa figuratam stellis inter sidera constituisse Apollinis et Iouis uoluntate, quod Orpheus Apollinem maxime laudaret; Iuppiter autem filiae beneficium concessit.

(Hygini Astronomi Astronomica 2 .7.1)

'Quinque neci Caeneus dederat Styphelumque Bromumque Antimachumque Elymumque securiferumque Pyracmon: vulnera non memini, numerum nomenque notavi. provolat Emathii spoliis armatus Halesi, quem dederat leto, membris et corpore Latreus maximus: huic aetas inter iuvenemque senemque, vis iuvenalis erat, variabant tempora cani. qui clipeo galeaque Macedoniaque sarisa conspicuus faciemque obversus in agmen utrumque armaque concussit certumque equitavit in orbem verbaque tot fudit vacuas animosus in auras: "et te, Caeni, feram? nam tu mibi femina semper, tu mibi Caenis eris. nec te natalis origo commonuit, mentemque subit, quo praemia facto quaque viri falsam speciem mercede pararis? 
quid sis nata, vide, vel quid sis passa, columque,

$i$, cape cum calathis et stamina pollice torque;

bella relinque viris."

(P. Ovidii Nasonis Metamorphoses 12. 459-476)

Qvi primi templa deorvm constitverunt. Aedem Ioui Olymp<i>o primum fecit Pelasgus Triopae filius in Arcadia. Thessalus templum [quod est in Macedonia] Iouis Dodonaei in terra Molossorum. Eleuther primus simulacrum Liberi patris constituit et quemadmodum coli debere $<t>$ ostendit. Phoroneus Inachi filius templum Argis Iunoni primus fecit. Otr<e $>$ ra Amazon Martis coniunx templum Dianae Ephesi prima fecit, quod postea a rege [...] restituerunt. Lycaon Pelasgi filius templum Mercurio Cyllenio in Arcadia fecit. Pierius [...]

(Hygini Fabulae 225)

Hoc tractu temporum, ante annos quinque et sexaginta quam urbs Romana conderetur, ab Elissa Tyria, quam quidam Dido autumant, Carthago conditur. Circa quod tempus Caranus, uir generis regii, sextus decimus ab Hercule, profectus Argis regnum Macedoniae occupauit; a quo Magnus Alexander cum fuerit septimus decimus, iure materni generis Achille auctore, paterni Hercule gloriatus est.

(Vellei Paterculi Historia Romana 1. 6.4-5)

Archelaus T<e>meni filius exsul a fratribus eiectus in Macedoniam ad regem Cisseum uenit, qui cum a finitimis oppugnaretur Archelao regnum et filiam in coniugium dare pollicetur si se ab boste tutatus esset Archelaus, quia ab Hercule esset oriundus, nam $T<e>$ menus Herculis filius fuit. qui hostes uno proelio fugauit et ab rege pollicita petit. ille ab amicis dissuasus fidem fraudauit eumque per dolum interficere uoluit. Itaque foueam iussit fieri et multos carbones eo ingeri et incendi et super uirgulta tenuia poni, quo cum Archelaus uenisset ut decideret. Hoc regis 
seruus Archelao patefecit; qui re cognita dicit se cum rege colloqui uelle secreto; arbitris semotis Archelaus regem arreptum in foueam coniecit atque ita eum perdidit. Inde profugit ex responso Apollinis in Macedoniam capra duce, oppidumque ex nomine caprae Aegeas constituit. Ab boc Alexander Magnus oriundus esse dicitur.

(Hygini Fabulae 219)

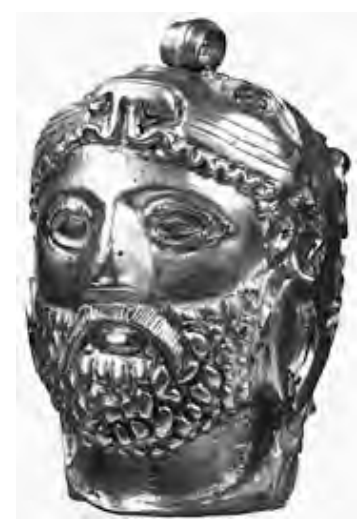

\section{Fortissimi dei Martis clientes}

In Asia clarissimae gentes: Indi, Seres, Persae, Medi, Parthi, Arabes, Bithyni, Phryges, Cappadoces, Cilices, Syri, Lydi. in Europa clarissimae gentes: Scythae, Sarmatae, Germani, Daci, Moesi, Thraci, Macedones, Dalmatae, Pannoni, Illyrici, Graeci, Itali, Galli, Spani. In Libya gentes clarissimae: Aethiopes, Mauri, Numidae, Poeni, Gaetuli, Garamantes, Nasamones, Aegyptii.

(Lucii Ampelii Liber Memorialis 6. 6)

Assyrii principes omnium gentium rerum potiti sunt, deinde Medi, postea Persae, deinde Macedones; exinde duobus regibus Philippo et Antiocho, qui a Macedonibus oriundi erant, haud multo post Carthaginem subactam deuictis summa imperii ad populum Romanum peruenit. inter 
hoc tempus et initium regis Nini Assyriorum, qui princeps rerum potitus $<$ est $>$, intersunt anni MDCCCCXCV.

(Aemilii Surae De annis populi Romani fr.1)

Imperia ab ineunte aevi memoria fuerunt septem: primi rerum potiti $s<u n t>$ Assyrii, deinde Medi, postea Persae, tum Lacedaemonii, dein Athenienses, post hos inde Macedones, sic deinde Romani.

(Lucii Ampelii Liber Memorialis 10. 1)

Philippus Amyntae filius primus Macedonum obtinuit Thraciam redegitque in suam potestatem; et cum transire in Asiam vellet, sub ipso belli apparatu in theatro a Pausania est interfectus. Alexander Philippi et Olympiadis filius ex urbe Pella Macedoniae cum milibus XL militum <cum> in Asiam transisset, Darium regem Persarum primum aput Granicum flumen tum aput Issum Ciliciae tertio apud Arbela tribus proeliis trecenta peditum quinquaginta equitum duo milia falcatorum curruum vicit. Mox regem Indorum et omnes Asiae gentes sub potestate $<m>s u a<m>$ redegit et nobilissimas urbes Asiae cepit Sardes Bactra Susa Babyloniam; ubi etiam defunctus dubium $a<n>$ vinolentia an veneno, cum tamen prius et Africam peragrasset usque ad Iovem Ammonem et Oceanum primus omnium navigasset. Philippus qui post Alexandrum [Macedoniam] septimo gradu Macedoniam regnavit, invectus in Graeciam cum saeve dominaretur a Sulpicio consule in Phocide victus est, mox a Flamini<n>o in [Macedonia] Thessalia aput Cynocephalas ubi dato obside filio Demetrio regni parte multatus est. Perses [Philippus] Philippi filius cum maximis copiis Macedoniis et Cum impetum in Graeciam fecisset, cum inanibus elephantorum simulacris a Marcio consule aput Ascyridam paludem victus praecipitatis in mare thesauris profugit; mox ab Aemilio Paulo tota Macedonia fugatus Samothracam confugit in asylum; unde data fide cum se Paulo commisisset, ante currum eius in triumphum productus mox libera custodia in Albano consenuit. Pseudophilippus vir plebeius et degener cum ex similitudine formae Philippi filium se persuasisset et Macedonas in bellum excitasset, inter 
initia tumultus comprehensus sub custodia missus est Romam; ubi cum ex custodia aufugisset, concitata rursus Macedonia Thraciam bello recepit. In arce regni paludatus ius dixit. mox a Caecilio Metello ingenti proelio victus cum profugisset in Thraciam, a regibus deditus et in triumphum deportatus.

(Lucii Ampelii Liber Memorialis 16. 1)

Ex Macedonum autem gente duo multo ceteros antecesserunt rerum gestarum gloria: Philippus, Amyntae filius, et Alexander Magnus. horum alter Babylone morbo consumptus est, Philippus Aegiis a Pausania, cum spectatum ludos iret, iuxta theatrum occisus est. unus Epirotes, Pyrrhus, qui cum populo Romano bellauit. is cum Argos oppidum oppugnaret in Peloponneso, lapide ictus interiit. unus item Siculus, Dionysius prior. nam et manu fortis et belli peritus fuit et, id quod in tyranno non facile reperitur, minime libidinosus, non luxuriosus, non auarus, nullius denique rei cupidus nisi singularis perpetuique imperii ob eamque rem crudelis: nam dum id studuit munire, nullius pepercit uitae, quem eius insidiatorem putaret. bic cum uirtute tyrannidem sibi peperisset, magna retinuit felicitate: maior enim annos sexaginta natus decessit florente regno. neque in tam multis annis cuiusquam ex sua stirpe funus uidit, cum ex tribus uxoribus liberos procreasset multique ei nati essent nepotes.

Fuerunt praeterea magni reges ex amicis Alexandri Magni, qui post obitum eius imperia ceperunt, in his Antigonus et huius filius Demetrius, Lysimachus, Seleucus, Ptolemaeus. ex his Antigonus in proelio, cum aduersus Seleucum et Lysimachum dimicaret, occisus est. pari leto affectus est Lysimachus ab Seleuco: namque societate dissoluta bellum inter se gesserunt. at Demetrius, cum filiam suam Seleuco in matrimonium dedisset neque eo magis fida inter eos amicitia manere potuisset, captus bello in custodia socer generi periit a morbo. neque ita multo post Seleucus a Ptolemaeo Cerauno dolo interfectus est, quem ille a patre expulsum Alexandrea alienarum opum indigentem receperat. ipse autem Ptolemaeus, cum uiuus filio regnum tradidisset, ab illo eodem uita priuatus dicitur. 
Macedo Alexander, cum ab ineunte aetate res maximas gerere coepisset, nonne tertio et tricesimo anno mortem obit? quae est aetas nostris legibus decem annis minor quam consularis. Ex quo iudicari potest virtutis esse quam aetatis cursum celeriorem.

(Ciceronis Philippicae 5. 48)

Item Aristotelis: 'Alexandro enim Macedoni neque in deliberando consilium neque in proeliando virtus neque in beneficio benignitas deerat, sed dumtaxat in supplicio crudelitas. Nam cum aliqua res dubia accidisset, apparebat sapientissimus: cum autem confligendum esset cum hostibus, fortissimus: cum vero praemium dignis tribuendum, liberalissimus: at cum animadvertendum, clementissimus.'

(P. Rutilii Lupi Schemata lexeos 1. 18)

Haec barbaris regibus feritas in ira fuit, quos nulla eruditio, nullus litterarum cultus inbuerat: dabo tibi ex Aristotelis sinu regem Alexandrum, qui Clitum carissimum sibi et una educatum inter epulas transfodit manu quidem sua, parum adulantem et pigre ex Macedone ac libero in Persicam seruitutem transeuntem. Nam Lysimachum aeque familiarem sibi leoni obiecit. Numquid ergo bic Lysimachus felicitate quadam dentibus leonis elapsus ob hoc, cum ipse regnaret, mitior fuit? Nam Telesphorum Rhodium amicum suum undique decurtatum, cum aures illi nasumque abscidisset, in cauea uelut nouum aliquod animal et inusitatum diu pauit, cum oris detruncati mutilatique deformitas humanam faciem perdidisset; accedebat fames et squalor et inluuies corporis in stercore suo destituti; callosis super haec genibus manibusque, quas in usum pedum angustiae loci cogebant, lateribus uero adtritu exulceratis non minus foeda quam terribilis erat forma eius uisentibus, factusque poena sua monstrum misericordiam quoque amiserat. Tamen, cum dissimillimus esset homini qui illa patiebatur, dissimilior erat qui faciebat. 


\section{Varia Macedonum strategemata}

De transducendo exercitu per loca hosti infesta: Philippus, Macedonum rex, Graeciam petens, cum Thermopylas occupatas audiret et ad eum legati Aetolorum venissent acturi de pace, retentis eis ipse magnis itineribus ad angustias pertendit securisque custodibus et legatorum reditus exspectantibus inopinatus Thermopylas traiecit.

(Sexti Iulii Frontini Strategemata 1. 4. 7)

Philippus, cum angustias maris, quae $\Sigma \tau \varepsilon v \dot{\alpha}$ appellantur, transnavigare propter Atheniensium classem, quae opportunitatem loci custodiebat, non posset, scripsit Antipatro Thraciam rebellare, praesidis quae ibi reliquerat interceptis: sequeretur omnibus omissis. quae ut epistulae interciperentur ab hoste, curavit: Athenienses, arcana Macedonum excepisse visi, classem abduxerunt; Philippus nullo probibente angustias freti liberavit.

Idem, quia Cherronessum, quae iuris Atheniensium erat, occupare probibebatur, tenentibus transitum non Byzantiorum tantum, sed Rhodiorum quoque et Chiorum navibus, conciliavit animos eorum reddendo naves, quas ceperat, quasi sequestres futuros ordinandae pacis inter se atque Byzantios, qui causa belli erant: tractaque per magnum tempus postulatione, cum de industria subinde aliquid in condicionibus retexeret, classem per id tempus praeparavit eaque in angustias freti imparato boste subitus evasit.

(Sexti Iulii Frontini Strategemata 1.4.13)

De acie ordinanda: Philippus, Macedonum rex, adversus Hyllios gerens bellum, ut animadvertit frontem hostium stipatam electis de toto exercitu viris, latera autem infirmiora, fortissimis suorum in dextro cornu collocatis, sinistrum latus hostium invasit turbataque tota acie victoriam profligavit. 
Circa annum deinde urbis conditae quadringentesimum Philippus, Amyntae filius, Alexandri pater, regnum Macedoniae adeptus est, inque eo tempore Alexander natus est, paucisque inde annis post Plato philosophus ad Dionysium Siciliae tyrannum posteriorem profectus est; post deinde aliquanto tempore Philippus apud Chaeroneam proelio magno Athenienses uicit. Tum Demosthenes orator ex eo proelio salutem fuga quaesiuit, cumque id ei, quod fugerat, probrose obiceretur, uersu

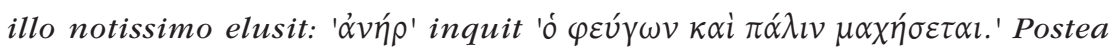
Philippus ex insidis occiditur; et Alexander regnum adeptus ad subigendos Persas in Asiam atque in Orientem transgressus est. Alter autem Alexander, cui cognomentum Molosso fuit, in Italiam uenit bellum populo Romano facturus-iam enim fama uirtutis felicitatisque Romanae apud exteras gentes enitescere inceptabat-, sed priusquam bellum faceret, uita decessit. Eum Molossum, cum in Italiam transiret, dixisse accepimus se quidem ad Romanos ire quasi in andronitin, Macedonem isse ad Persas quasi in gynaeconitin. Postea Macedo Alexander pleraque parte orientali subacta, cum annos undecim regnauisset, obit mortis diem. Neque ita longe post Aristoteles philosophus et post aliquanto Demosthenes uita functi sunt, isdemque ferme tempestatibus populus Romanus graui ac diutino Samnitium bello conflictatus est, consulesque Tiberius Veturius et Spurius Postumius in locis iniquis apud Caudium a Samnitibus circumuallati ac sub iugum missi turpi foedere facto discesserunt ob eamque causam populi iussu Samnitibus per fetiales dediti recepti non sunt.

(Auli Gellii Noctes Atticae 17. 21.28-36)

Alexander Macedo, probibente rege Indorum Poro traici exercitum per flumen Hydaspen, adversus aquam assidue procurrere iussit suos: et ubi eo more exercitationis assecutus est, $<n e>q u i<d>$ a Poro adversa ripa caveretur, per superiorem partem subitum transmisit exercitum.

Idem, quia Indi fluminis traiectu probibebatur ab hoste, diversis locis in flumen equites instituit immittere et transitum minari; cumque exspectatione barbaros intentos teneret, insulam paulo remotiorem primum exiguo, deinde maiore praesidio occupavit atque inde in ulteriorem 
ripam transmisit: ad quam manum opprimendam cum universi se hostes effudissent, ipse libero vado transgressus omnes copias coniunxit.

(Sexti Iulii Frontini Strategemata 1. 4. 10)

Quemadmodum ea, quibus defici<e>mur, videantur non deesse aut usus eorum expleatur: [Non alienus, ut arbitror, bic locus est referendi factum Alexandri Macedonis illud nobile, qui per deserta Africae itinera gravissima siti cum exercitu affectus oblatam sibi a milite in galea aquam spectantibus universis effudit, utilior exemplo temperantiae, quam si communicare potuisset.]

(Sexti Iulii Frontini Strategemata 1. 7. 7)

Quemadmodum incitandus sit ad proelium exercitus: Alexander Macedo sacrificaturus inscripsit medicamento haruspicis manum, quam ille extis erat suppositurus. litterae significabant victoriam Alexandro dari: quas cum iecur calidum rapuisset et a rege militi esset ostensum, auxit animum tamquam deo spondente victoriam. Idem fecit $<S>$ udines haruspex proelium Eumene cum Gallis commissuro.

(Sexti Iulii Frontini Strategemata 1. 11. 14)

Alexander ad Arbela, cum hostium multitudinem vereretur, virtuti autem suorum fideret, aciem in omnem partem spectantem ordinavit, ut circumventi undique pugnare possent.

Paulus adversus Persen Macedonum regem, cum is phalangem suorum duplicem mediam in partem direxisset eamque levi armatura cinxisset et equitem utroque cornu collocasset, triplicem aciem cuneis instruxit, inter quos velites subinde emisit. quo genere cum profligari nibil videret, cedere instituit, ut hac simulatione perduceret hostes in confragosa loca, quae ex industria captaverat. cum sic quoque, suspecta calliditate recedentium, ordinata sequeretur phalanx, equites a sinistro cornu praeter oram phalangis iussit transcurrere citatis equis, tectos, ut obiectis armis ipso impetu 
praefringerent bostium spicula: quo genere telorum exarmati Macedones solverunt aciem et terga verterunt.

(Sexti Iulii Frontini Strategemata 2. 3. 19-20)

De insidiis: Alexander Macedo, cum hostis in saltu editiore castra communisset, subducta parte copiarum praecepit his, quos relinquebat, ut ex more ignes <ex>citarent speciemque praeberent totius exercitus: ipse per avias regiones circumducta manu hostem superiore aggressus loco depulit.

(Sexti Iulii Frontini Strategemata I2. 5. 17)

De effectu disciplinae: Alexander Macedo XL milibus hominum iam inde a Philippo patre disciplinae assuefactis orbem terrarum aggressus innumerabiles hostium copias vicit.

(Sexti Iulii Frontini Strategemata 4. 2. 4)

De affectu et moderatione: Alexander, cum bieme duceret exercitum, residens ad ignem recognoscere praetereuntis copias coepit; cumque conspexisset quendam prope exanimatum frigore, considere loco suo iussit dixitque ei: "Si in Persis natus esses, in regia sella resedisse tibi capital foret, in Macedonia nato conceditur."

(Sexti Iulii Frontini Strategemata I4. 6. 3)

De dubiorum animis in fide retinendis: Alexander devicta perdomitaque Thracia petens Asiam, veritus, ne post ipsius discessum sumerent arma, reges eorum praefectosque et omnis, quibus videbatur inesse cura detractae libertatis, secum velut honoris causa traxit, ignobilis autem relictis plebeiosque praefecit, consecutus, uti principes beneficiis eius obstricti nibil novare vellent, plebs vero ne posset quidem, spoliata principibus.

Antipater, conspecto Peloponesiorum exercitu, qui audita morte Alexandri ad infestandum imperium eius confluxerant, dissimulans scire 
se, qua mente venissent, gratias his egit, quod ad auxilium ferendum Alexandro adversus Lacedaemonios convenissent, adiecitque id se regi scripturum, ceterum ipsos, quia sibi opera eorum in praesentia non esset necessaria, abirent domos, hortatus: et hac asseveratione periculum, quod ex novitate rerum imminebat, discussit.

Alexandrum quoque Macedonem traditum est eximiae pulchritudinis virgini captivae, cum finitimae gentis principi fuisset desponsa, summa abstinentia ita pepercisse, ut illam ne aspexerit quidem: qua mox ad sponsum remissa, universae gentis per hoc beneficium animos conciliavit sibi.

(Sexti Iulii Frontini Strategemata 2. 11. 3,4,6)

De emittendo boste, ne clausus proelium ex desperatione redintegret: Antigonus, rex Macedonum, Aetolis, qui in obsidionem ab eo compulsi fame urguebantur statuerantque eruptione facta commori, viam fugae dedit: atque ita infracto impetu eorum insecutus aversos cecidit.

(Sexti Iulii Frontini Strategemata 2. 6. 5)

De eliciendis ad proditionem: Lysimachus, rex Macedonum, cum Ephesios oppugnaret et illi in auxilio haberent Mandronem archipiratam, qui plerumque oneratas praeda naves Ephesum appellebat, corrupto ei ad proditionem iunxit fortissimos Macedonum, quos ille restrictis manibus pro captivis Ephesum introduceret: postea raptis ex arce armis urbem Lysimacho tradiderunt.

(Sexti Iulii Frontini Strategemata 3. 3. 7)

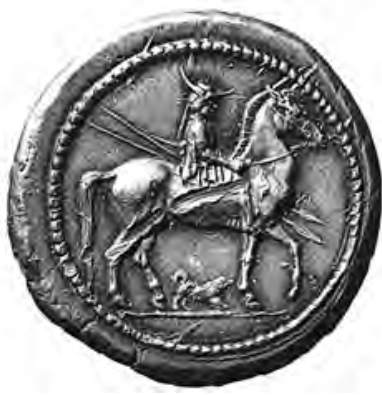




\section{Quid inter Indos, Persas, Aegyptiosque Macedonicus sermo}

A caelestibus agedum te ad humana conuerte: uidebis gentes populosque uniuersos mutasse sedem. Quid sibi uolunt in medis barbarorum regionibus Graecae urbes? Quid inter Indos Persasque Macedonicus sermo? Scythia et totus ille ferarum indomitarumque gentium tractus ciuitates Achaiae Ponticis inpositas litoribus ostentat: non perpetuae biemis saeuitia, non bominum ingenia ad similitudinem caeli sui borrentia transferentibus domos suas obstiterunt. Atheniensis in Asia turba est; Miletus quinque et septuaginta urbium populum in diuersa effudit; totum Italiae latus quod infero mari adluitur maior Graecia fuit. Tuscos Asia sibi uindicat; Tyrii Africam incolunt, [in] Hispaniam Poeni; Graeci se in Galliam inmiserunt, in Graeciam Galli; Pyrenaeus Germanorum transitus non inhibuit-per inuia, per incognita uersauit se bumana leuitas. Liberos coniugesque et graues senio parentes traxerunt. Alii longo errore iactati non iudicio elegerunt locum sed lassitudine proximum occupauerunt, alii armis sibi ius in aliena terra fecerunt; quasdam gentes, cum ignota peterent, mare hausit, quaedam ibi consederunt ubi illas rerum omnium inopia deposuit.

(L. Annaei Senecae Iunioris Dialogi 12. 7. 1-3)

Reges Parthorum: [...] Seleucus Alexandri Macedonis amicus; cuius post mortem ab Arrbida<eo> fratre eius iussus Babylonem optinere finitimos sub se redegit (unde Nicator est appellatus) et tres validissimas urbes constituit Antiochiam Seleuciam Laodiciam... [...] Eumenes alius qui Romanos Macedonico bello iuvit cum milite suo.

(Lucii Ampelii Liber Memorialis 31. 2; 33. 2)

Reges Alexandriae: Post mortem Alexandri Macedonis regnaverunt Alexandriae Aegyptum [octo] Ptolomaei nomine multi clarissimi viri. Ptolomaeus Soter qui Alexandrum aput Oxydracas obiecto clipeo protexit. Ptolomaeus <eius> filius Philadelphus litteratissimus qui plurimos 
libros Graecos scripsit. Ptolomaeus Euergetes qui ingenti classe Rhodios vicit. Ptolomaeus Physcon qui seditiosos in theatro sagittis occidit alios flammis dedit. Huius filius Cyprius pro Romanis multa bella gessit adversus Garamantas et Indos. Ptolomaeus Pupillus dictus qui Pompeium tutorem a senatu accepit donec pubesceret et postea civili bello $<a>$ Pothino interfectus est.

(Lucii Ampelii Liber Memorialis 35. 1-6)

Zmyrnaeum conventum magna pars et Aeoliae, quae mox dicetur, frequentat praeterque Macedones Hyrcani cognominati et Magnetes a Sipylo. verum Ephesum, alterum lumen Asiae, remotiores conveniunt Caesarienses, Metropolitae, Cilbiani Inferiores et Superiores, Mysomacedones, M<as $>$ taurenses, Briullitae, Hypaepeni, Dioshieritae.

(C. Plinii Secundi Naturalis Historia 5. 119-120)

Iuxta vero ab ortu ex Indico mari sub eodem sidere pars tota vergens in Caspium mare pernavigata est Macedonum armis Seleuco atque Antiocho regnantibus, qui et Seleucida et Antiochida ab ipsis appellari voluere. et circa Caspium multa oceani litora explorata parvoque brevius quam totus hinc aut illinc septentrio eremigatus, ut $<i>a m$ coniecturae locum sic quoque non relinquat ingens argumentum paludis Maeoticae, sive ea illius oceani sinus est, ut multos adverto credidisse, sive angusto discreti situ restagnatio. alio latere Gadium ab eodem occidente magna pars meridiani sinus ambitu Mauretaniae navigatur hodie. maiorem quidem eius partem et orientis victoriae Magni Alexandri lustravere usque in Arabicum sinum, in quo res gerente C. Caesare Augusti filio signa navium ex Hispaniensibus naufragiis feruntur agnita.

(C. Plinii Secundi Naturalis Historia I2. 167-169)

Namque Persarum regna, quae nunc Parthorum intellegimus, inter duo maria Persicum et Hyrcanium Caucasi iugis attolluntur. utrimque per devexa 
laterum Armeniae Maiori a frontis parte, quae vergit in Commagenen, Cephenia, ut diximus, copulatur eique Adiabene, Assyriorum initium, cuius pars est Arbilitis, ubi Darium Alexander debellavit, proxime Syriae. totam eam Macedones $M<y>$ gdoniam cognominaverunt a similitudine. oppida Alexandria, item Antiochia quam Nesebin vocant; abest ab Artaxatis DCCL $p$. fuit et Ninos, inposita Tigri, ad solis occasum spectans, quondam clarissima. reliqua vero fronte, quae tendit ad Caspium mare, Atrapatene, ab Armenia<e> Otene regione discreta Araxe. oppidum eius Gazae, ab Artaxat<is> CCCCL p., totidem ab Ecbatanis Medorum, quorum pars sunt Atrapateni.

(C. Plinii Secundi Naturalis Historia 6. 41-42)

Mesopotamia tota Assyriorum fuit, vicatim dispersa praeter Babylona et Ninum. Macedones eam in urbes congregavere propter ubertatem soli. oppida praeter iam dicta habet Seleuciam, La<o>diceam, Artemitam; item in Arabum gente qui $<$ O $>$ rroei vocantur et Ma $<r>$ dani Antiochiam, quae a praefecto Mesopotamiae Nicanore condita Arabis vocatur. iunguntur his Arabes introrsus Eldamari ...

(C. Plinii Secundi Naturalis Historia 6. 117)

Charax, oppidum Persici sinus intimum, a quo Arabia Eudaemon cognominata excurrit, habitatur in colle manu facto inter confluentes dextra Tigrim, laeva Eulaeum, II p. laxitate. conditum est primum ab Alexandro Magno, colonis ex urbe regia Durine, quae tum interiit, deductis, militum inutilibus ibi relictis; Alexandriam appellari iusserat pagumque Pell<a>eum a patria sua, quem proprie Macedonum fecerat. flumina id oppidum expugnavere; postea restituit Antiochus quintus regum et suo nomine appellavit, iterumque infestatum Spaosines Sagdodonaci filius, rex finitimorum Arabum, quem Iuba satrapen Antiochi fuisse falso tradit, oppositis molibus restituit nomenque suum dedit, emunito situ iuxta in longitudinem VI p., in latitudinem paulo minus.

(C. Plinii Secundi Naturalis Historia 6. 138) 
At Tiridates volentibus Parthis Nicephorium et Anthemusiada ceterasque urbes, quae Macedonibus sitae Graeca vocabula usurpant, Halumque et Artemitam Parthica oppida recepit, certantibus gaudio qui Artabanum Scythas inter eductum ob saevitiam execrati come Tiridatis ingenium Romanas per artes sperabant.

(C. Taciti Annales 6. 41)

Magna pars Iudaeae vicis dispergitur, habent et oppida; Hierosolyma genti caput. illic immensae opulentiae templum, et primis munimentis urbs, dein regia, templum intimis clausum. ad fores tantum Iudaeo aditus, limine praeter sacerdotes arcebantur. dum Assyrios penes Medosque et Persas Oriens fuit, despectissima pars servientium: postquam Macedones praepolluere, rex Antiochus demere superstitionem et mores Graecorum dare adnisus, quo minus taeterrimam gentem in melius mutaret, Parthorum bello probibitus est; nam ea tempestate Arsaces desciverat. tum Iudaei Macedonibus invalidis, Parthis nondum adultis (et Romani procul erant), sibi ipsi reges imposuere; qui mobilitate vulgi expulsi, resumpta per arma dominatione fugas civium, urbium eversiones, fratrum coniugum parentum neces aliaque solita regibus ausi superstitionem fovebant, quia bonor sacerdotii firmamentum potentiae adsumebatur.

(C. Taciti Historiae 5. 8)

Sed iure laudetur in litore Aegyptii maris Alexandria, a Magno Alexandro condita in Africae parte ab ostio Canopico XII p. iuxta Mareotim lacum, qui locus antea Rhacotes nominabatur. metatus est eam Dinochares architectus pluribus modis memorabili ingenio, XV p. laxitate insessa ad effigiem Macedonicae chlamydis orbe gyrato laciniosam, dextra laevaque anguloso procursu, iam tum tamen quinta situs parte regiae dicata. Mareotis lacus a meridiana urbis parte euripo e Canopico ostio mittit ex mediterraneo commerci<a>, insulas quoque plures amplexus, XXX traiectu, $C<C L>$ ambitu, ut tradit Claudius Caesar. alii schoenos in longitudinem patere XL faciunt schoenumque stadia $X X X$ : 
ita fieri longitudinis CL p., tantundem et latitudinis. sunt in bonore et intra decursus Nili multa oppida, praecipue quae nomina ostiis dedere, non omnibus - XII enim reperiuntur superque quattuor, quae ipsi falsa ora appellant-, sed celeberrimis VII, proximo Alexandriae Canopico, dein Bolbitino, Sebennytico, Phatmitico, Mendesico, Tanitico ultimoque Pelusiaco. praeterea Butos, Pharb $<a e>t<b>0 s$, Leontopolis, At $<b>$ ribis, Isidis oppidum, Busiris, Cynopolis, Aphrodites, Sais, Naucratis, unde ostium quidam Naucratiticum nominant quod alii Heracleoticum, Canopico, cui proximum est, praeferentes.

(C. Plinii Secundi Naturalis Historia 5. 62-64)

Ptolemaeo regi, qui Macedonum primus Aegypti opes firmavit, cum Alexandriae recens conditae moenia templaque et religiones adderet, oblatum per quietem decore eximio et maiore quam humana specie iuvenem, qui moneret ut fidissimis amicorum in Pontum missis effigiem suam acciret; laetum id regno magnamque et inclutam sedem fore quae excepisset: simul visum eundem iuvenem in caelum igne plurimo attolli. Ptolemaeus omine et miraculo excitus sacerdotibus Aegyptiorum, quibus mos talia intellegere, nocturnos visus aperit. atque illis Ponti et externorum parum gnaris, Timotheum Atheniensem e gente Eumolpidarum, quem ut antistitem caerimoniarum Eleusine exciverat, quaenam illa superstitio, quod numen, interrogat. Timotheus quaesitis qui in Pontum meassent, cognoscit urbem illic Sinopen, nec procul templum vetere inter accolas fama Iovis Ditis: namque et muliebrem effigiem adsistere quam plerique Proserpinam vocent. sed Ptolemaeus, ut sunt ingenia regum, pronus ad formidinem, ubi securitas redit, voluptatum quam religionum adpetens neglegere paulatim aliasque ad curas animum vertere, donec eadem species terribilior iam et instantior exitium ipsi regnoque denuntiaret ni iussa patrarentur. tum legatos et dona Scydrothemidi regi (is tunc Sinopensibus imperitabat) expediri iubet praecepitque navigaturis ut Pythicum Apollinem adeant. illis mare secundum, sors oraculi haud ambigua: irent simulacrumque patris sui reveherent, sororis relinquerent. Vt Sinopen venere, munera preces mandata regis sui Scydrothemidi 
adlegant. qui <di>versus animi modo numen pavescere, modo minis adversantis populi terreri; saepe donis promissisque legatorum flectebatur. atque interim triennio exacto Ptolemaeus non studium, non preces omittere: dignitatem legatorum, numerum navium, auri pondus augebat. tum minax facies Scydrothemidi offertur ne destinata deo ultra moraretur: cunctantem varia pernicies morbique et manifesta caelestium ira graviorque in dies fatigabat. advocata contione iussa numinis, suos Ptolemaeique visus, ingruentia mala exponit: vulgus aversari regem, invidere Aegypto, sibi metuere templumque circumsedere. maior hinc fama tradidit deum ipsum adpulsas litori navis sponte conscendisse: mirum inde dictu, tertio die tantum maris emensi Alexandriam adpelluntur. templum pro magnitudine urbis extructum loco cui nomen Rhacotis; fuerat illic sacellum Serapidi atque Isidi antiquitus sacratum. haec de origine et advectu dei celeberrima. nec sum ignarus esse quosdam qui Seleucia urbe Syriae accitum regnante Ptolemaeo, quem tertia aetas tulit; alii auctorem eundem Ptolemaeum, sedem, ex qua transierit, Memphim perbibent, inclutam olim et veteris Aegypti columen. deum ipsum multi Aesculapium, quod medeatur aegris corporibus, quidam Osirin, antiquissimum illis gentibus numen, plerique Iovem ut rerum omnium potentem, plurimi Ditem patrem insignibus, quae in ipso manifesta, aut per ambages coniectant.

(C. Taciti Historiae 4. 83-84)

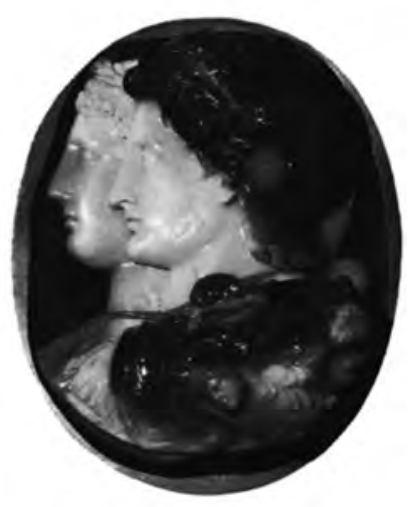




\section{Macedonum memorabilia}

Epistula Philippi regis ad Aristotelem philosophum super Alexandro recens nato. Philippus, Amyntae filius, terrae Macedoniae rex, cuius uirtute industriaque Macetae locupletissimo imperio aucti gentium nationumque multarum potiri coeperant et cuius uim atque arma toti Graeciae cauenda metuendaque inclitae illae Demosthenis orationes contionesque uocificant, is Philippus, cum in omni fere tempore negotiis belli uictoriisque adfectus exercitusque esset, a liberali tamen Musa et a studiis humanitatis numquam afuit, quin lepide comiterque pleraque et faceret et diceret. Feruntur adeo libri epistularum eius munditiae et uenustatis et prudentiae plenarum, uelut sunt illae litterae, quibus Aristoteli philosopho natum esse sibi Alexandrum nuntiauit. Ea epistula, quoniam curae diligentiaeque in liberorum disciplinas hortamentum est, exscribenda uisa est ad commonendos parentum animos. Exponenda est igitur ad hanc ferme sententiam: 'Philippus Aristoteli salutem dicit. Filium mibi genitum scito. Quod equidem dis habeo gratiam, non proinde quia natus est, quam pro eo, quod eum nasci contigit temporibus uitae tuae. Spero enim fore, ut eductus eruditusque a te dignus exsistat et nobis et rerum istarum susceptione.'

(Auli Gellii Noctes Atticae I9. 3. 1-6)

Philippus Macedonum rex habebat militem manu fortem, cuius in multis expeditionibus utilem expertus operam subinde ex praeda aliquid illi virtutis causa donaverat et hominem venalis animae crebris auctoramentis accendebat. Hic naufragus in possessiones cuiusdam Macedonis expulsus est; quoi ut nuntiatum est, accucurrit, spiritum eius recollegit, in villam illum suam transtulit, lectulo suo cessit, adfectum semianimemque recreavit, diebus triginta sua inpensa curavit, refecit, viatico instruxit subinde dicentem: 'Gratiam tibi referam, videre tantum mibi imperatorem meum contingat.' Narravit Philippo naufragium suum, auxilium tacuit et protinus petit, ut sibi cuiusdam praedia donaret. Ille quidam erat hospes eius, is ipse, a quo receptus erat, a quo sanatus. Multa interim reges in bello praesertim opertis oculis donant. 'Non sufficit bomo iustus tot armatis 
cupiditatibus, non potest quisquam eodem tempore et bonum virum et bonum ducem agere. Quomodo tot milia hominum insatiabilia satiabuntur? Quid habebunt, si suum quisque habuerit?' Haec Philippus sibi dixit, cum illum induci in bona, quae petebat, iussit. Expulsus bonis suis ille non ut rusticus iniuriam tacitus tulit contentus, quod non et ipse donatus esset, sed Philippo epistulam strictam ac liberam scripsit; qua accepta ita exarsit, ut statim Pausaniae mandaret, bona priori domino restitueret, ceterum inprobissimo militi, ingratissimo hospiti, avidissimo naufrago stigmata inscriberet ingratum hominem testantia. Dignus quidem fuit, cui non inscriberentur illae litterae, sed insculperentur, qui hospitem suum nudo et naufrago similem in id, <in> quo iacuerat ipse, litus expulerat; sed videbimus, quis modus poenae servandus fuerit: auferendum utique fuit, quod summo scelere invaserat. Quis autem poena eius moveretur? id conmiserat, propter quod nemo misereri misericors posset.

Dabit tibi Philippus, quia promisit, etiam si non debet, etiam si iniuriam facturus est, etiam si scelus facturus est, etiam si uno facto praeclusurus est naufragis litora? Non est levitas a cognito et damnato errore discedere, et ingenue fatendum est: 'Aliud putavi, deceptus sum.' Haec vero superbae stultitiae perseverantia est: 'Quod semel dixi, qualecumque est, fixum ratumque sit.' Non est turpe cum re mutare consilium. Age, si Philippus possessorem illum eorum litorum reliquisset, quae naufragio ceperat, non omnibus miseris aqua et igni interdixerat? 'Potius' inquit 'intra fines regni mei tu litteras istas oculis inscribendas durissima fronte circumfer. I, ostende, quam sacra res sit mensa hospitalis; praebe in facie tua legendum istuc decretum, quo cavetur, ne miseros tecto iuvare capital sit. Magis ista constitutio sic rata erit, quam si illam in aes incidissem.'

(L. Annaei Senecae Iunioris De beneficiis 4. 37-38)

Eodem oraculo Macedonum rex Philippus admonitus ut a quadrigae uiolentia salutem suam custodiret, toto regno disiungi currus iussit eumque locum, qui in Boeotia Quadriga uocatur, semper uitauit. nec tamen denuntiatum periculi genus effugit: nam Pausanias in capulo gladii, quo eum occidit, quadrigam habuit caelatam. 
Quae tam pertinax necessitas in patre filio Alexandro consimilis apparuit: si quidem Callanus Indus sua sponte se ardenti rogo superiecturus, interpellatus ab eo ecquid aut mandaret aut dicere uellet, 'breui te' inquit 'uidebo': nec id sine causa, quia uoluntarium eius e uita excessum rapida mors Alexandri subsecuta est.

(Valerii Maximi Facta et dicta Memorabilia 1. 8. 11)

Age, Philippi quam probabilis epistola, in qua Alexandrum quorumdam Macedonum beniuolentiam largitione ad se adtrabere conatum sic increpuit: 'quae te, fili, ratio in hanc tam uanam spem induxit, ut eos tibi fideles futuros existimares, quos pecunia ad amorem tui conpulisses?' a caritate istud pater, ab usu Philippus, maiore ex parte mercator Graeciae quam uictor.

Aristoteles autem Callisthenen auditorem suum ad Alexandrum dimittens monuit cum eo aut quam rarissime aut quam iucundissime loqueretur, quo scilicet apud regias aures uel silentio tutior uel sermone esset acceptior. at ille, dum Alexandrum Persica Macedonem salutatione gaudentem obiurgat et ad Macedonicos mores inuitum reuocare beniuole perseuerat, spiritu carere iussus seram neglecti salubris consilii paenitentiam egit.

(Valerii Maximi Facta et dicta Memorabilia 7. 2. 10)

Alexander Macedonum rex discere geometriam coeperat, infelix, sciturus quam pusilla terra esset, ex qua minimum occupaverat. Ita dico: 'infelix' ob boc quod intellegere debebat falsum se gerere cognomen: quis enim esse magnus in pusillo potest? Erant illa quae tradebantur subtilia et diligenti intentione discenda, non quae perciperet vesanus bomo et trans oceanum cogitationes suas mittens. 'Facilia' inquit 'me doce'. Cui praeceptor 'ista' inquit 'omnibus eadem sunt, aeque difficilia'. Hoc puta rerum naturam dicere: 'ista de quibus quereris omnibus eadem sunt; nulli dare faciliora possum, sed quisquis volet sibi ipse illa reddet faciliora'. Quomodo? aequanimitate. Et doleas oportet et sitias et esurias et senescas (si tibi longior contigerit inter bomines mora) et aegrotes et perdas aliquid 
et pereas. Non est tamen quod istis qui te circumstrepunt credas: nibil horum malum est, nihil intolerabile aut durum. Ex consensu istis metus est.

(L. Annaei Senecae Iunioris Epistulae Morales ad Lucilium 91. 17-18)

Vetusto Macedoniae more regi Alexandro nobilissimi pueri praesto erant sacrificanti. e quibusunus turibulo arrepto ante ipsum adstitit. in cuius brachium carbo ardens delapsus est. quo etsi ita urebatur, ut adusti corporis eius odor ad circumstantium nares perueniret, tamen et dolorem silentio pressit et brachium inmobile tenuit, ne sacrificium Alexandri aut concusso turibulo impediret aut edito gemitu re $<l i>$ gio $<n e>$ aspergeret. rex, quo patientia pueri magis delectatus est, hoc certius perseuerantiae experimentum sumere uoluit: consulto enim sacrificauit diutius nec hac re eum proposito repulit. si huic miraculo Dareus inseruisset oculos, scisset eius stirpis milites uinci non posse, cuius infirmam aetatem tanto robore praeditam animaduertisset.

(Valerii Maximi Facta et dicta Memorabilia 3. 3. 1)

Quam bene Macedoniae rex Alexander per quietem uisa imagine praemonitus erat ut uitae suae custos esset diligentior, si eum cauendi etiam periculi consilio fortuna instruere uoluisset: namque Cassandri pestiferam sibi dexteram somnio prius cognouit quam exitu sensit: existimauit enim ab illo se interfici, cum eum numquam uidisset. interposito deinde tempore postquam in conspectum uenit, nocturni metus patefacta imagine, ut Antipatri filium esse cognouit, adiecto uersu Graeco, qui fidem somniorum eleuat, praeparati iam aduersus caput suum ueneficii, quo occidisse Cassandri manu creditur, suspicionem animo repulit.

(Valerii Maximi Facta et dicta Memorabilia 1. 7. 3)

Commemoratione Romani exempli in Macedoniam deductus morum Alexandri praeconium facere cogor, cuius ut infinitam gloriam bellica uirtus, ita praecipuum amorem clementia meruit. is, dum omnes gentes 
infatigabili cursu lustrat, quodam loci niuali tempestate oppressus senio iam confectum Macedonem militem nimio frigore obstupefactum ipse sublimi et propinqua igni sede residens animaduertit factaque non fortunae, sed aetatis utriusque aestimatione descendit et illis manibus, quibus opes Darii adflixerat, corpus frigore duplicatum in suam sedem inposuit: id ei salutare futurum, quod apud Persas capital extitisset, solium regium occupasse. quid ergo mirum est, si sub eo duce tot annis militare iucundum ducebant, cui gregarii militis incolumitas proprio fastigio carior erat? idem non hominum ulli, sed naturae fortunaeque cedens, quamquam uiolentia morbi dilabebatur, in cubitum tamen erectus dexteram omnibus, qui eam contingere uellent, porrexit. quis autem illam osculari non cuperet, quae iam fato oppressa maximi exercitus conplexui bumanitate quam spiritu uiuidior suffecit?

(Valerii Maximi Facta et dicta Memorabilia 5. 1. 1)

Quod sequitur et rei ipsius admiratione et claritate auctoris inlustre. Alexander Macedonum rex incluta iam pugna excellentissimis opibus Darei contusis aestu et itineris feruore in Cilicia percalefactus Cydno, qui aquae liquore conspicuus Tarson interfluit, corpus suum inmersit. subito deinde ex nimio haustu frigoris obstupefactis neruis ac torpore hebetatis artubus maxima cum exanimatione totius exercitus in oppidum castris propinquum defertur. iacebat aeger Tarsi, inque ualitudine eius aduersa instantis uictoriae spes fluctuabat. itaque conuocati medici adtentissimo consilio salutis remedia circumspiciebant. quorum cum ad unam potionem <se> sententiae direxissent, atque eam Philippus medicus suis manibus temperatam Alexandro -erat autem ipsius amicus et comes-porrexisset, a Parmenione missae litterae superueniunt admonentes ut rex insidias Philippi perinde ac pecunia corrupti a Dareo caueret. quas cum legisset, sine ulla cunctatione medicamentum hausit ac tum legendas Philippo tradidit. pro quo tam constanti erga amicum iudicio dignissimam a dis inmortalibus mercedem recepit, qui incolumitatis eius praesidium falso interpellari indicio noluerunt.

(Valerii Maximi Facta et dicta Memorabilia 3. 8. 6) 
Cum Alexander Macedonum rex sorte monitus ut eum, qui sibi porta egresso primus occurrisset, interfici iuberet, asinarium forte <ante> omnis obuiam factum ad mortem abripi imperasset, eoque quaerente quidnam se immerentem capitali supplicio innocentemque addiceret, cum ad excusandum factum suum oraculi praeceptum retulisset, asinarius, 'si ita est' inquit, 'rex, alium sors buic morti destinauit: nam asellus, quem ego ante me agebam, prior tibi occurrit'. delectatus Alexander et illius tam callido dicto et quod ipse ab errore reuocatus erat, occasionem in aliquanto uiliore animali expiandae religionis rapuit. summa in boc mansuetudo, in alterius regis equisone calliditas.

(Valerii Maximi Facta et dicta Memorabilia 7. 3. 1)

Et haec quidem uiuo Scipioni, illud autem Aemilio Paulo exanimi contigit: nam cum exequiae eius celebrarentur ac forte tunc principes Macedoniae legationis nomine Romae morarentur, funebri lecto sponte sua sese subiecerunt. quod aliquanto maius uidebitur, si qui cognoscat lecti illius frontem Macedonicis triumphis fuisse adornatam: quantum enim Paulo tribuerunt, propter quem gentis suae cladium indicia per ora uulgi ferre non exhorruerunt! quod spectaculum funeri speciem alterius triumphi adiecit: bis enim te, Paule, Macedonia urbi nostrae inlustrem ostendit, incolumem spoliis suis, fato functum umeris.

(Valerii Maximi Facta et dicta Memorabilia 2. 10.3)

Alexander Macedonum rex gloriari solebat a nullo se beneficiis victum. Non est, quod nimius animi Macedonas et Graecos et Caras et Persas et nationes discriptas in exercitum suspiciat, nec hoc sibi praestitisse regnum <a> Thraciae angulo porrectum usque ad litus incogniti maris iudicet; eadem re gloriari Socrates potuit, eadem Diogenes, a quo utique victus est. Quidni victus sit illo die, quo bomo super mensuram iam bumanae superbiae tumens vidit aliquem, cui nec dare quicquam posset nec eripere? Archelaus rex Socratem rogavit, ut ad se veniret; dixisse Socrates traditur nolle se ad eum venire, a quo acciperet beneficia, cum reddere illi paria non posset. 
Primum in ipsius potestate erat non accipere; deinde ipse dare beneficium prior incipiebat, veniebat enim rogatus et id dabat, quod utique ille non erat Socrati redditurus; etiamnunc Archelaus daturus erat aurum et argentum recepturus contemptum auri et argenti: non poterat referre Archelao Socrates gratias? Et quid tantum erat accepturus, quantum dabat, si ostendisset hominem vitae ac mortis peritum utriusque fines tenentem? si regem in luce media errantem ad rerum naturam admisisset usque eo eius ignarum, ut, quo die solis defectio fuit, regiam cluderet et filium, quod in luctu ac rebus adversis moris est, tonderet? Quantum fuisset beneficium, si timentem e latebris suis extraxisset et bonum animum habere iussisset dicens: "Non est ista solis defectio, sed duorum siderum coitus, cum luna bumiliore currens via infra ipsum solem orbem suum posuit et illum obiectu sui abscondit; quae modo partes eius exiguas, si in transcursu strinxit, obducit, modo plus tegit, si maiorem partem sui obiecit, modo excludit totius adspectum, si recto libramento inter solem terrasque media successit. Sed iam ista sidera hoc et illo diducet velocitas sua; iam recipient diem terrae, et hic ibit ordo per saecula dispositosque ac praedictos dies habet, quibus sol intercursu lunae vetetur omnes radios effundere. Paulum expecta; iam emerget, iam istam velut nubem relinquet, iam exolutus inpedimentis lucem suam libere mittet." Socrates parem gratiam Archelao referre non posset, si illum regnare vetuisset? parum scilicet magnum beneficium a Socrate accipiebat, si ullum dare Socrati potuisset. Quare ergo hoc Socrates dixit? Vir facetus et cuius per figuras sermo procederet, derisor omnium, maxime potentium, maluit illi nasute negare quam contumaciter aut superbe; dixit se nolle beneficia ab eo accipere, cui non posset paria reddere.

(L. Annaei Senecae Iunioris De beneficiis 5. 6. 1-6)

Alexandro Macedoni, cum victor Orientis animos supra bumana tolleret, Corinthii per legatos gratulati sunt et civitate illum sua donaverunt. Cum risisset hoc Alexander officii genus, unus ex legatis: 'Nulli' inquit 'civitatem umquam dedimus alii quam tibi et Herculi.' Libens accepti non dilutum honorem et legatos invitatione aliaque bumanitate prosecutus cogitavit, non qui sibi civitatem darent, sed cui dedissent; et 
bomo gloriae deditus, cuius nec naturam nec modum noverat, Herculis Liberique vestigia sequens ac ne ibi quidem resistens, ubi illa defecerant, ad socium honoris sui respexit a dantibus, tamquam caelum, quod mente vanissima conplectebatur, teneret, quia Herculi aequabatur. Quid enim illi simile habebat vesanus adulescens, cui pro virtute erat felix temeritas? Hercules nibil sibi vicit; orbem terrarum transivit non concupiscendo, sed iudicando, quid vinceret, malorum hostis, bonorum vindex, terrarum marisque pacator; at bic a pueritia latro gentiumque vastator, tam hostium pernicies quam amicorum, qui summum bonum duceret terrori esse cunctis mortalibus, oblitus non ferocissima tantum, sed ignavissima quoque animalia timeri ob malum virus.

(L. Annaei Senecae Iunioris De beneficiis 1. 13)

At sunt quidam extra omnem subducti cupiditatem, qui vix ullis humanis desideriis continguntur; quibus nibil potest praestare ipsa fortuna. Necesse est a Socrate beneficiis vincar, necesse est a Diogene, qui per medias Macedonum gazas nudus incessit calcatis regiis opibus; o! ne ille tunc merito et sibi et ceteris, quibus ad dispiciendam veritatem non erat obfusa caligo, supra eum eminere visus est, infra quem omnia iacebant; multo potentior, multo locupletior fuit omnia tunc possidente Alexandro; plus enim erat, quod bic nollet accipere, quam quod ille posset dare. Non est turpe ab his vinci; neque enim minus fortis sum, si cum involnerabili me hoste conmittis, nec ideo minus ignis urere potest, si in materiam incidit inviolabilem flammis, nec ideo ferrum secandi vim perdidit, si non recipiens ictum lapis solidusque et invictae adversus dura naturae dividendus est. Idem tibi de homine grato respondeo: non turpiter vincitur beneficiis, si ab his obligatus est, ad quos aut fortunae magnitudo aut eximia virtus aditum redituris ad se beneficiis clusit.

(L. Annaei Senecae Iunioris De beneficiis 5. 4. 3-5.2)

Refer Alexandri Macedonis exemplum, qui Clitum carissimum sibi ac fidelissimum inter epulas transfodit et intellecto facinore mori voluit, 
certe debuit. Omne vitium ebrietas et incendit et detegit, obstantem malis conatibus verecundiam removet; plures enim pudore peccandi quam bona voluntate probibitis abstinent. Ubi possedit animum nimia vis vini, quidquid mali latebat emergit.

(L. Annaei Senecae Iunioris Epistulae Morales ad Lucilium 83. 19)

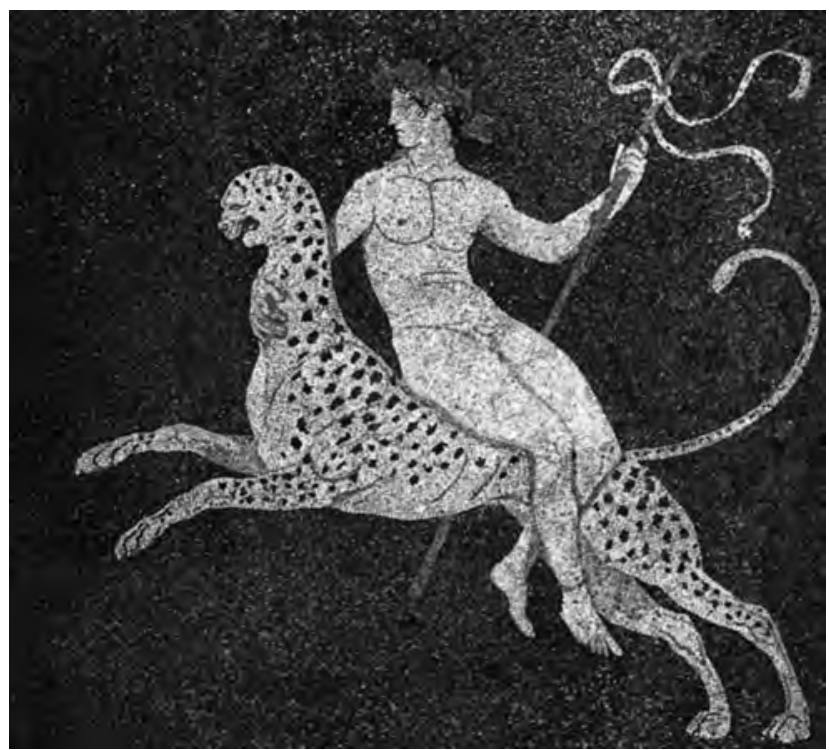

\section{Pauca de artibus}

Quem enim oratorem Lacedaemonium, quem Cretensem accepimus? quarum civitatum severissima disciplina et severissimae leges traduntur. ne Macedonum quidem ac Persarum aut ullius gentis, quae certo imperio contenta fuerit, eloquentiam novimus. Rhodii quidam, plurimi Athenienses oratores extiterunt, apud quos omnia populus, omnia imperiti, omnia, ut sic dixerim, omnes poterant. nostra quoque civitas, donec erravit, donec se partibus et dissensionibus et discordiis confecit, donec nulla fuit in foro pax, nulla in senatu concordia, nulla in iudicis moderatio, nulla superiorum reverentia, nullus magistratuum 
modus, tulit sine dubio valentiorem eloquentiam, sicut indomitus ager habet quasdam herbas laetiores. sed nec tanti rei publicae Gracchorum eloquentia fuit, ut pateretur et leges, nec bene famam eloquentiae Cicero tali exitu pensavit.

(C. Taciti Dialogus de oratoribus 40. 3-4)

Mulieres fere omnes in maiorem modum exosus fuisse dicitur, siue quod natura abborruit a mulierum coetu siue quod duas simul uxores habuerat, cum id decreto ab Atheniensibus facto ius esset, quarum matrimonii pertaedebat. Eius odii in mulieres Aristophanes quoque meminit

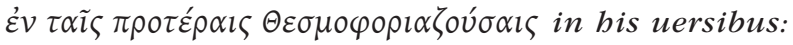

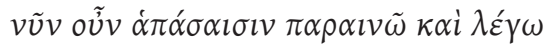

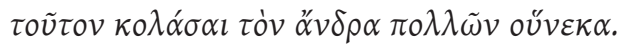
$\ddot{\alpha} \gamma \rho \imath \alpha \gamma \dot{\alpha} \rho \dot{\eta} \mu \tilde{\alpha} \varsigma, \tilde{\omega} \gamma v v \alpha \tilde{\imath} \kappa \varepsilon \varsigma, \delta \rho \tilde{\alpha} \kappa \alpha \kappa \dot{\alpha}$

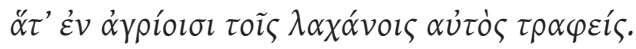

Alexander autem Aetolus hos de Euripide uersus composuit:

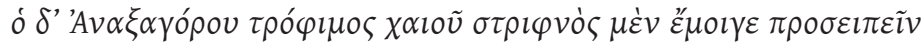

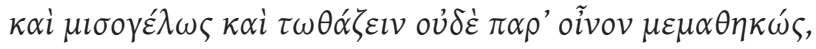

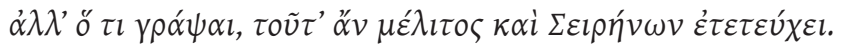

Is, cum in Macedonia apud Archelaum regem esset utereturque eo rex familiariter, rediens nocte ab eius cena canibus a quodam aemulo inmissis dilaceratus est, et ex his uulneribus mors secuta est. Sepulchrum autem eius et memoriam Macedones eo dignati sunt honore, ut in gloriae quoque loco prae-

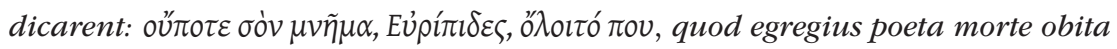
sepultus in eorum terra foret. Quamobrem cum legati ad eos ab Atheniensibus missi petissent, ut ossa Athenas in terram illius patriam permitterent transferri, maximo consensu Macedones in ea re deneganda perstiterunt.

(Auli Gellii Noctes Atticae 15. 20. 6-10) 
Sed atrocius aliquanto Euripides finitus est: ab Archelai enim regis cena in Macedonia domum hospitalem repetens, canum morsibus laniatus obiit: crudelitas fati tanto ingenio non debita.

(Valerii Maximi Facta et dicta Memorabilia 9. 12.4)

Euxinidas hac aetate docuit Aristiden, praeclarum artificem, Eupompus Pamphilum, Apellis praeceptorem. est Eupompi victor certamine gymnico palmam tenens. ipsius auctoritas tanta fuit, ut diviserit picturam: genera, quae ante eum duo fuere-Helladicum et Asiaticum appellabant-, propter bunc, qui erat Sicyonius, diviso Helladico tria facta sunt, Ionicum, Sicyonium, Atticum. Pamphili cognatio et proelium ad Phliuntem ac victoria Atheniensium, item Ulixes in rate. ipse Macedo natione, sed Primus in pictura omnibus litteris eruditus, praecipue arithmetica et geometria, sine quibus negabat artem perfici posse, docuit neminem talento minoris-annuis D-, quam mercedem et Apelles et Melanthius dedere ei. huius auctoritate effectum est Sicyone primum, deinde in tota Graecia, ut pueri ingenui omnia ante graphicen, boc est picturam in buxo, docerentur recipereturque ars ea in primum gradum liberalium. semper quidem honos ei fuit, ut ingenui eam exercerent, mox ut honesti, perpetuo interdicto ne servitia docerentur. ideo neque in bac neque in toreutice ullius, qui servierit, opera celebrantur.

\section{(C. Plinii Secundi Naturalis Historia 35. 75-77)}

Dinocrates architectus cogitationibus et sollertia fretus, cum Alexander rerum potiretur, profectus est e Macedonia ad exercitum regiae cupidus commendationis. is e patria a propinquis et amicis tulit ad primos ordines et purpuratos litteras, ut aditus haberet faciliores, ab eisque exceptus humane petit, uti quamprimum ad Alexandrum perduceretur. cum polliciti essent, tardiores fuerunt idoneum tempus expectantes. itaque Dinocrates ab his se existimans ludi ab se petit praesidium. fuerat enim amplissima statura, facie grata, forma dignitateque summa. his igitur naturae muneribus confisus vestimenta posuit in bospitio et oleo 
corpus perunxit caputque coronavit populea fronde, laevum umerum pelle leonina texit, dextraque clavam tenens incessit contra tribunal regis ius dicentis. novitas populum cum avertisset, conspexit eum Alexander. admirans ei iussit locum dari, ut accederet, interrogavitque, quis esset. at ille: 'Dinocrates', inquit, 'architectus Macedo, qui ad te cogitationes et formas adfero dignas tuae claritati. namque Atbon montem formavi in statuae virilis figuram, cuius manu laeva designavi civitatis amplissimae moenia, dextera pateram, quae exciperet omnium fluminum, quae sunt in eo monte, aquam, ut inde in mare profunderetur'. delectatus Alexander ratione formae statim quaesit, si essent agri circa, qui possent frumentaria ratione eam civitatem tueri. cum invenisset non posse nisi transmarinis subvectionibus: 'Dinocrates', inquit, 'attendo egregiam formae compositionem et ea delector, sed animadverto, si qui deduxerit eo loci coloniam, fore ut iudicium eius vituperetur. ut enim natus infans sine nutricis lacte non potest ali neque ad vitae crescentis gradus perduci, sic civitas sine agris et eorum fructibus in moenibus affluentibus non potest crescere nec sine abundantia cibi frequentiam habere populumque sine copia tueri. itaque quemadmodum formationem puto probandam, sic iudico locum inprobandum; teque volo esse mecum, quod tua opera sum usurus'. ex eo Dinocrates ab rege non discessit et in Aegyptum est eum persecutus. ibi Alexander cum animadvertisset portum naturaliter tutum, emporium egregium, campos circa totam Aegyptum frumentarios, inmanis fluminis Nili magnas utilitates, iussit eum suo nomine civitatem Alexandriam constituere. ita Dinocrates a facie dignitateque corporis commendatus ad eam nobilitatem pervenit. mibi autem, imperator, staturam non tribuit natura, faciem deformavit aetas, valetudo detraxit vires. itaque quoniam ab his praesidiis sum desertus, per auxilia scientiae scriptaque, ut spero, perveniam ad commendationem.

(Vitruvii Pollionis De architectura 2. pr.1-3)

Lysippum Sicyonium Duris negat ullius fuisse discipulum, sed primo aerarium fabrum audendi rationem cepisse pictoris Eupompi responso. eum enim interrogatum, quem sequeretur antecedentium, dixisse monstrata 
hominum multitudine, naturam ipsam imitandam esse, non artificem. plurima ex omnibus signa fecit, ut diximus, fecundissimae artis, inter quae destringentem se, quem M. Agrippa ante Thermas suas dicavit, mire gratum Tiberio principi. non quivit temperare sibi in eo, quamquam imperiosus sui inter initia principatus, transtulitque in cubiculum alio signo substituto, cum quidem tanta pop. $R$. contumacia fuit, ut theatri clamoribus reponi apoxyomenon flagitaverit princepsque, quamquam adamatum, reposuerit. nobilitatur Lysippus et temulenta tibicina et canibus ac venatione, in primis vero quadriga cum Sole Rhodiorum. fecit et Alexandrum Magnum multis operibus, a pueritia eius orsus, quam statuam inaurari iussit Nero princeps delectatus admodum illa; dein, cum pretio perisset gratia artis, detractum est aurum, pretiosiorque talis existimabatur etiam cicatricibus operis atque concisuris, in quibus aurum haeserat, remanentibus. idem fecit Hephaestionem, Alexandri Magni amicum, quem quidam Polyclito adscribunt, cum is centum prope annis ante fuerit; item Alexandri venationem, quae Delphis sacrata est, Athenis Satyrum, turmam Alexandri, in qua amicorum eius imagines summa omnium similitudine expressit; hanc Metellus Macedonia subacta transtulit Romam. fecit et quadrigas multorum generum. statuariae arti plurimum traditur contulisse capillum exprimendo, capita minora faciendo quam antiqui, corpora graciliora siccioraque, per quae proceritas signorum maior videretur. non habet Latinum nomen symmetria, quam diligentissime custodit nova intactaque ratione quadratas veterum staturas permutando, vulgoque dicebat ab illis factos quales essent homines, a se quales viderentur esse. propriae huius videntur esse argutiae operum custoditae in minimis quoque rebus.

(C. Plinii Secundi Naturalis Historia 34. 61-65)

Aristophanes vero, cum ab eo sententia rogaretur, eum primum renuntiari iussit, qui minime populo placuisset. cum autem rex et universi vehementer indignarentur, surrexit et rogando impetravit, ut paterentur se dicere. itaque silentio facto docuit unum ex his eum esse poetam, ceteros aliena recitavisse; oportere autem iudicantes non furta sed scripta probare. admirante populo et rege dubitante, fretus memoriae certis armariis 
infinita volumina eduxit et ea cum recitatis conferendo coegit ipsos furatos de se confiteri. itaque rex iussit cum his agi furti condemnatosque cum ignominia dimisit, Aristophanen vero amplissimis muneribus ornavit et supra bybliothecam constituit. insequentibus annis a Macedonia Zoilus, qui adoptavit cognomen, ut Homeromastix vocitaretur, Alexandriam venit suaque scripta contra Iliadem et Odyssean comparata regi recitavit. Ptolomaeus vero, cum animadvertisset poetarum parentem philologiaeque omnis ducem absentem vexari et, cuius ab cunctis gentibus scripta suspicerentur, ab eo vituperari, indignans nullum ei dedit responsum. Zoilus autem, cum diutius in regno fuisset, inopia pressus summisit ad regem postulans, ut aliquid sibi tribueretur. rex vero respondisse dicitur Homerum, qui ante annos mille decessisset, aevo perpetuo multa milia hominum pascere, item debere, qui meliore ingenio se profiteretur, non modo unum sed etiam plures alere posse. et ad summam mors eius ut parricidii damnati varie memoratur. alii enim scripserunt a Philadelpho esse in crucem fixum, nonnulli Chii lapides esse coniectos, alii Zmyrnae vivum in pyram coniectum. quorum utrum ei acciderit, merenti digna constitit poena; non enim aliter videtur promereri, qui citat eos, quorum responsum, quid senserint scribentes, non potest coram indicari. ego vero, Caesar, neque alienis indicibus mutatis interposito nomine meo id profero corpus neque ullius cogitata vituperans institui ex eo me adprobare, sed omnibus scriptoribus infinitas ago gratias, quod egregiis ingeniorum sollertiis ex aevo conlatis abundantes alius alio genere copias praeparaverunt, unde nos uti fontibus haurientes aquam et ad propria proposita traducentes facundiores et expeditiores habemus ad scribendum facultates talibusque confidentes auctoribus audemus institutiones novas comparare.

(Vitruvii Pollionis De architectura 7.pr.7-10)

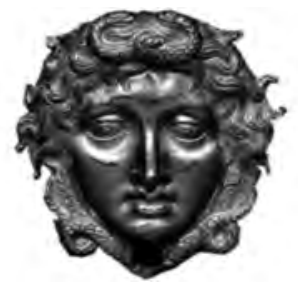




\section{Macedonum cum Romanis contentio}

Populus Romanus cum quibus gentibus bella conseruit et quibus de causis: [...] Pyrrhus rex Epirotarum qui pro Tarentinis bellum cum Romanis gessit vastataque Campania ad vicesimum ab urbe <lapidem> pervenit; mox a Curio et Fabricio victus in patriam concessit, et cum Achaiam armis sub se redegisset, Macedoniam quoque Antigono regi eripuit, sed dum Argos expugnat occisus est. Omnium Graecorum sapientissimus et militaris disciplinae peri<ti>ssimus fuit.

(Lucii Ampelii Liber Memorialis 28. 3)

[De bello Macedonico] Populus Romanus cum Macedonibus bellum ter gessit: sub Flaminino consule regem eorum Philippum vicit, sub Paulo Persen Philippi filium, sub Metello Macedonico Pseudophilippum. primi belli causa quod de iniuriis Macedonum Graeci querebantur; secundi quod foedus cum patre suo percussum ruperit Perses; tertii quod falso nomen regium Macedonum Pseudophilippus invasit.

(Lucii Ampelii Liber Memorialis 44. 1-5)

Nostri maiores, maximi scilicet viri, ab hostibus tantum res repetierunt, beneficia magno animo dabant, magno perdebant; excepta Macedonum gente non est in ulla data adversus ingratum actio. Magnumque boc argumentum est dandam non fuisse, quia adversus maleficium omne consensimus, et homicidii, veneficii, parricidii, violatarum religionum aliubi atque aliubi diversa poena est, sed ubique aliqua, boc frequentissimum crimen nusquam punitur, ubique inprobatur; neque absolvimus illud, sed cum difficilis esset incertae rei aestimatio, tantum odio damnavimus et inter ea reliquimus, quae ad iudices deos mittimus.

(L. Annaei Senecae Iunioris De beneficiis 3. 6. 2)

Namque Romanis cum nationibus populis regibus cunctis una et ea vetus causa bellandi est: cupido profunda imperi et divitiarum. qua primo 
cum rege Macedonum Philippo bellum sumpsere, dum a Carthaginiensibus premebantur, amicitiam simulantes. ei subvenientem Antiochum concessione Asiae per dolum avortere, ac mox fracto Philippo Antiochus omni cis Taurum agro et decem milibus talentorum spoliatus est. Persen deinde, Philippi filium, post multa et varia certamina apud Samothracas deos acceptum in fidem callidi et repertores perfidiae, quia pacto vitam dederant, insomniis occidere. Eumen<en>, quoius amicitiam gloriose ostentant, initio prodidere Antiocho pacis mercedem; post, habitum custodiae agri captivi, sumptibus et contumelis ex rege miserrumum servorum effecere, simulatoque inpio testamento filium eius Aristonicum, quia patrium regnum petiverat, hostium more per triumphum duxere; Asia ab ipsis obsessa est. postremo Bithyniam Nicomede mortuo diripuere, quom filius Nysa, quam reginam appellaverat, genitus haud dubie esset.

(C. Sallustii Crispi Historiarum fragmenta ampliora, Mithr. 16-35)

Post Carthaginem vinci neminem puduit. secutae sunt statim Africam gentes, Macedonia, Graecia, Syria ceteraque omnia quodam quasi aestu et torrente fortunae, sed primi omnium Macedones, adfectator quondam imperii populus. itaque quamvis tum Philippus regno praesideret, Romani tamen dimicare sibi cum rege Alexandro videbantur. Macedonicum bellum nomine amplius quam spectatione gentis fuit. causa coepit a foedere Philippi, quo rex iam pridem dominantem in Italia Hannibalem sibi socium iunxerat; postea crevit inplorantibus Athenis auxilium contra regis iniurias, cum ille ultra ius victoriae in templa et aras et sepulcra ipsa saeviret. placuit senatui opem tantis ferre supplicibus. quippe iam gentium reges duces, populi nationes praesidia sibi ab hac urbe repetebant. primum igitur Laevino consule populus Romanus Ionium mare ingressus, tota Graeciae litora veluti triumphanti classe peragravit. spolia quippe Siciliae Sardiniae, Hispaniae Africae praeferebat, et manifestam victoriam nata in praetoria puppi laurus pollicebatur. aderat sponte in auxilium Attalus, rex Pergamenorum, aderant Rhodii, nauticus populus, qui navibus a mari, consul a terris omnia equis virisque quatiebat. bis victus, bis fugatus rex, bis exutus castris, cum tamen nibil terribilius Macedonibus fuit ipso 
volnerum adspectu, quae non spiculis nec sagittis nec ullo Graeculo ferro sed ingentibus pilis nec minoribus adacta gladiis ultra mortem patebant. enimvero Flaminino duce invios antea Chaonum montes Aoumque amnem per abrupta vadentem et ipsa Macedoniae claustra penetravimus. introisse victoria fuit. nam postea numquam ausus congredi rex ad tumulos, quos Cynocephalas vocant, uno ac ne hoc quidem iusto proelio opprimitur. et illi quidem consul pacem dedit regnumque concessit, mox, ne quid esset bostile, Thebas et Euboean et grassantem sub Nabide suo Lacedaemona compescuit. Graeciae vero veterem statum reddidit, ut legibus viveret suis et avita libertate frueretur. quae gaudia, quae vociferationes fuerunt, cum boc forte Nemeae in theatro quinquennalibus ludis a praecone caneretur! quo certavere plausu! quid florum in consulem profuderunt! et iterum iterumque praeconem repetere vocem illam iubebant, qua libertas Achaiae pronuntiabatur, nec aliter illa consulari sententia quam modulatissimo aliquo tibiarum aut fidium cantu fruebantur.

(Annii Flori Epitome Bell. Omn. Ann. DCC 1. 23)

Dum aliae aliaeque gentes Syriaci belli secuntur ruinam, Macedonia rursus se erexit. fortissimum populum memoria et recordatio suae nobilitatis agitabat, et successerat Philippo filius Perses, qui semel in perpetuum victam esse Macedoniam non putabat ex gentis dignitate. multo vehementius sub hoc Macedones quam sub patre consurgunt. quippe Thracas in vires suas traxerant, atque ita industriam Macedonum viribus Thracum, ferociam Thracum disciplina Macedonica temperavere. accessit his consilium ducis, qui situm regionum suarum a summo speculatus Haemo positis per abrupta castris ita Macedoniam suam armis ferroque vallaverat, ut non reliquisse aditum nisi a caelo venturis hostibus videretur. tamen Marcio Philippo consule eam provinciam ingressus populus Romanus, exploratis diligenter accessibus per Ascurida paludem Perrbaebosque tumulos illa volucribus quoque, ut videbantur, invia accessit, regemque securum et nibil tale metuentem subita belli inruptione deprehendit. cuius tanta trepidatio fuit, ut pecuniam omnem in mare iusserit mergi ne periret, classem cremari ne incenderetur. Paulo consule, cum maiora et crebriora essent inposita 
praesidia, per alias vias Macedonia deprensa est, summa quidem arte et industria ducis, cum eminatus alia inrepsisset. cuius adventus ipse adeo terribilis regi fuit, ut interesse non auderet, sed gerenda ducibus bella mandaverit. absens ergo victus fugit in maria insulamque Samothracen, fretus celebri religione, quasi templa et arae possent defendere, quem nec montes sui nec arma potuissent. nemo regum diutius amissae fortunae conscientiam retinuit. supplex cum scriberet ad imperatorem ab illo quo confugerat templo nomenque epistolae notaret suum, regem addidit. sed nec reverentior captae maiestatis alius Paulo fuit. cum in conspectum venisset hostis, in tribunali recepit et convivis adbibuit liberosque admonuit suos ut fortunam, cui tantum liceret, revererentur. inter pulcherrimos bunc quoque populus Romanus de Macedonia duxit ac vidit triumphum; quippe cuius spectaculo triduum impleverit. primus dies signa tabulasque, sequens arma pecuniam transvexit, tertius captivos ipsumque regem adtonitum adbuc tamquam subito malo et stupentem. sed multo prius gaudium victoriae populus Romanus quam epistolis victoris praeceperat. quippe eodem die, quo victus est Perses in Macedonia, Romae cognitum est: duo iuvenes candidis equis apud Iuturnae lacum pulverem et cruorem abluebant. hi nuntiavere. Castorem et Pollucem fuisse creditum volgo, quod gemini fuissent; interfuisse bello, quod sanguine maderent; a Macedonia venire, quod adbuc anbelarent.

(Annii Flori Epitome Bell. Omn. Ann. DCC 1.28)

Quodam fato, quasi ita convenisset inter Poenos et Macedonas ut tertio quoque vincerentur, eodem tempore utrique arma moverunt. sed prior iugum excutit Macedo, aliquanto quam ante gravior, dum contemnitur. causa belli prope erubescenda. quippe regnum pariter et bellum vir ultimae sortis Andriscus invaserat, dubium liber an servus, mercennarius certe; sed qui volgo Philippus ex similitudine Philippi Persae filii vocabatur, regiam formam, regium nomen, animum quoque regis inplevit. igitur dum haec ipsa contemnit, populus Romanus Iuventio praetore contentus, virum non Macedonicis modo, sed Thraciae quoque auxiliis ingentibus validum temere temptavit invictusque a veris regibus ab illo imaginario et scaenico rege superatus est. sed consul Metellus amissum cum legione 
praetorem plenissime ultus est. nam et Macedoniam servitute multavit et ducem belli deditum ab eo, ad quem confugerat, Thraciae regulo in urbem in catenis reduxit, hoc quoque illi in malis suis indulgente fortuna, ut de eo populus Romanus quasi de rege vero triumpharet.

(Annii Flori Epitome Bell. Omn. Ann. DCC 1.30)

Ciuitas Rodiensis et insulae oportunitate et operum nobilitatibus et nauigandi sollertia naualibusque uictoriis celebrata est. Ea ciuitas, cum amica atque socia populi Romani foret, Persa tamen, Philippi filio, Macedonum rege, cum quo bellum populo Romano fuit, amico usa est, conixique sunt Rodienses legationibus Romam saepe missis id bellum inter eos componere. Sed ubi ista pacificatio perpetrari nequiuit, uerba a plerisque Rodiensibus in contionibus eorum ad populum facta sunt, ut, si pax non fieret, Rodienses regem aduersus populum Romanum adiutarent. Sed nullum super ea re publicum decretum factum est. At ubi Perses uictus captusque est, Rodienses pertimuere ob ea, quae conpluriens in coetibus populi acta dictaque erant, legatosque Romam miserunt, qui temeritatem quorundam popularium suorum deprecarentur et fidem consiliumque publicum expurgarent.

(Auli Gellii Noctes Atticae 6. 3. 1-5)

Clarissimi duces Romanorum: [...] Paulus qui cum Macedoniam vicisset et Graeciam liberasset et opulentissimum triumphum reportasset, inter ipsos triumphi dies amissis duobus liberis pro contione dixit gratias se agere fortunae, quod in suam potius domum quam in rem publicam saevisset. Duo Metelli; quorum alter Macedonicus devictis Macedonibus qui Contrebiam inexpugnabilem Hispaniae civitatem iussis testamenta scribere et vetitis redire nisi vicissent militibus occupavit; alter Numidicus victa Numidia qui, cum perniciosas rei publicae leges ferret Apuleius tribunus plebis totusque senatus in eas iurasset, maluit in exilium ire quam iurare. Huius filius Pius cognominatus est, quod patrem in exilium secutus est. 
$<$ Populus Romanus $>$ per Flamini $<$ n $>$ um consulem Macedonas vicit; per Paulum consulem <item Macedonas > sub rege Perse <re>bellantes; per Scipiones Africanos Carthaginienses; per Scipionem <Asiaticum $>$ in Syria vicit regem Antiochum; per Scipionem Aemilianum Celtiberos et Numantiam; per eundem Scipionem Lusitaniam et ducem Viriatum; per Decimum Brutum Gallaeciam; per Mummium Achaicum [et] Corinthum et Achaeos; per Fulvium Nobiliorem Aetolos et Ambraciam; per Marium Numidas et Iugurtham; per eundem Marium Cimbros et Teutones; per Syllam Ponticos et Mithridatem; per Lucullum item <Ponticos et Mithridatem; per Pompeium> eosdem Ponticos et Mithridatem, item Cilicas piratas et Armenios cum rege Tigrane et plurimas Asia<ti>cas gentes; sub hoc enim duce ad Indicum Oceanum et Rubrum mare usque pervenit; per Gaium Caesarem Gallias Germanias Britanniam; sub hoc duce non tantum vidit sed etiam navigavit Oceanum; per Caesarem Augustum Dalmat[i]as Pannonios Illyricos Aegyptios Germanos Cantabros totumque orbem perpacavit exceptis Indis Parthis Sarmatis Scythis Dacis quod eos fortuna Traiani principis triumphis reservavit.

(Lucii Ampelii Liber Memorialis 48. 1-7)

Tum senatus populusque Romanus L. Aemilium Paulum, qui et praetor et consul triumphauerat, uirum in tantum laudandum in quantum intellegi uirtus potest, consulem creauit, filium eius Pauli qui, ad Cannas, quam tergiuersanter perniciosam rei publicae pugnam inierat, tam fortiter in ea mortem obierat. Is Persam ingenti proelio, apud urbem nomine Pydnam, in Macedonia, fusum fugatumque castris exuit, deletisque eius copiis, destitutum omni spe, coegit e Macedonia profugere, quam ille linquens in insulam Samothraciam profugit templique se religioni supplicem credidit.

(Vellei Paterculi Historia Romana 1. 9. 3-4)

At Byzantii data dicendi copia, cum magnitudinem onerum apud senatum deprecarentur, cuncta repetivere. orsi a foedere, quod nobiscum icerant, qua tempestate bellavimus adversus regem Macedonum, cui ut degeneri Pseudophilippi vocabulum impositum, missas posthac copias 
in Antiochum Persen Aristonicum et piratico bello adiutum Antonium memorabant, quaeque Sullae aut Lucullo aut Pompeio obtulissent, mox recentia in Caesares merita, quando ea loca insiderent quae transmeantibus terra marique ducibus exercitibusque, simul vehendo commeatu opportuna forent.

(C. Taciti Annales 12. 62)

Post uictum captumque Persen, qui quadriennio post in libera custodia Albae decessit, Pseudophilippus, a Mendacio simulatae originis appellatus, qui se Philippum regiaeque stirpis ferebat, cum esset ultimae, armis occupata Macedonia, adsumptis regni insignibus, breui temeritatis poenas dedit. Quippe Q. Metellus praetor, cui ex uirtute Macedonici nomen inditum erat, praeclara uictoria ipsum gentemque superauit et immani etiam Achaeos rebellare incipientes fudit acie. Hic est Metellus Macedonicus qui porticus, quae fuerunt circumdatae duabus aedibus sine inscriptione positis, quae nunc Octauiae porticibus ambiuntur, fecerat, quique hanc turmam statuarum equestrium quae frontem aedium spectant, hodieque maximum ornamentum eius loci, ex Macedonia detulit. Cuius turmae hanc causam referunt Magnum Alexandrum impetrasse a Lysippo, singulari talium auctore operum, ut eorum equitum, qui ex ipsius turma apud Granicum flumen ceciderant, expressa similitudine figurarum faceret statuas et ipsius quoque is interponeret. Hic idem primus omnium Romae aedem ex marmore in is ipsis monumentis molitus uel magnificentiae uel luxuriae princeps fuit.

(Vellei Paterculi Historia Romana 1. 11.2-5)

Auri in aerario populi R. fuere Sex. Iulio L. Aurelio cos., septem annis ante bellum Punicum tertium, pondo XVII CCCCX, argenti $\overline{X X I I} L X X$, et in numerato $|\overline{L X I}| \overline{X X X V}$ CCCC, Sexto Iulio L. Marcio cos., hoc est belli socialis initio, auri $|\overline{X V I}| \overline{X X}$ DCCCXXXI. C. Caesar primo introitu urbis civili bello suo ex aerario protulit laterum aureorum $\overline{X V}$, argenteorum 
$\overline{X X X}$, et in numerato $\overline{C C C}$. nec fuit aliis temporibus res p. locupletior. intulit et Aemilius Paulus Perseo rege victo e Macedonica praeda MMM, a quo tempore populus Romanus tributum pendere desiit.

(C. Plinii Secundi Naturalis Historia 33. 55-56)

Quippe non delicta regum illos, sed vires ac maiestatem insequi, neque in uno se, sed in aliis quoque omnibus hac saepe arte grassatos. Sic et avum suum Pharnacen per cognitionum arbitria succidaneum regi Pergameno Eumeni datum; sic rursus Eumenen, cuius classibus primo in Asiam fuere transiecti, cuius exercitu magis quam suo et magnum Antiochum et Gallos in Asia et mox in Macedonia regem Perseum domuerant, et ipsum pro hoste Habitum eique interdictum Italia, et quod cum ipso deforme sibi putaverant, cum filio eius Aristonico bellum gessisse.

(Pompei Trogi Historiae Philippicae 38. fr.152, 75-84)

Se autem, seu nobilitate illis conparetur, clariorem illa conluvie convenarum esse, qui paternos maiores suos a Cyro Darioque, conditoribus Persici regni, maternos a Magno Alexandro ac Nicatore Seleuco, conditoribus imperii Macedonici, referat, seu populus illorum conferatur suo, earum se gentium esse, quae non modo Romano imperio sint pares, sed Macedonico quoque obstiterint. Nullam subiectarum sibi gentium expertam peregrina imperia; nullis umquam nisi domesticis regibus paruisse; Cappadociam velint an Paphlagoniam recensere, rursus Pontum an Bithyniam, itemque Armeniam maiorem minoremque; quarum gentium nullam neque Alexander ille, qui totam pacavit Asiam, nec quisquam successorum eius aut posterorum attigisset. Scythiam duos umquam ante se reges non pacare, sed tantum intrare ausos, Darium et Philippum, aegre inde fugam sibi expedisse, unde ipse magnam adversus Romanos partem virium haberet.

(Pompei Trogi Historiae Philippicae 38. fr.152, 100-116) 


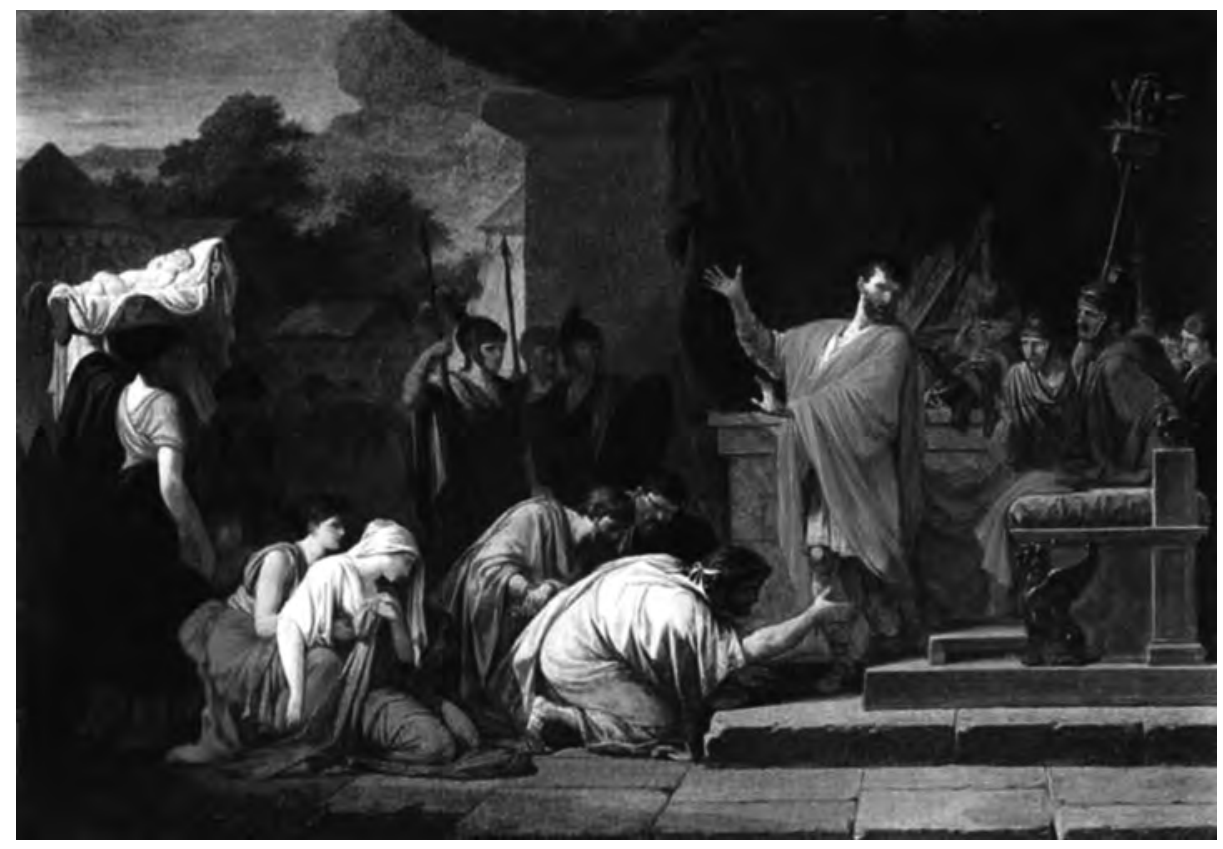

\section{Provincia non turribus, sed tropaeis munita}

Regii, qui $A<b>$ der $<a>e$ praesideba<n>t, captis Philippis dilabuntur. Colloquium Syllae et Archelauo in Aulide fuit et condiciones impositae, si rex pacem mallet. Quibus ille tandem paruit. Nam et Fimbriae adventum timebat, ut mox ordine indicabo, et se de conventis nibil novaturum Sulla praedixerat. Fuerunt autem hae: Archelauus classem traderet Sullae, rex insulis omnibus, Asia, Bitbynia, Paphlagonia decederet, item Gallograecis. Q. Oppium et $M^{\prime}$. Aquilium legatos redderet; item ceteros omnis captivos, quorum non parvus numerus erat, dimitteret. Inprimis excepti Macedones, quorum fides insignis fuerat, ut uxores et liberi redderentur. Praeterea naves <sept>uaginta tectas instructas sociis daret, frumentum, <vestem $>$, stipendium ipse praestaret. Is ipse Mithridates cum Sulla apud Dardanum compositis, gratia $<P$. $R$. > reconciliata, Ariobardianen ut servum respuit, reliqua classe in Pontum proficiscitur. Ac dum de condicionibus disceptatur, M<a>edos et Dardanos, qui socios vexabant, Hortensius $<l>e<$ gatus $>$ fugaverat . 
ipse Sulla ex<er>citum in $M<a>e d i<c>a m$ ind $<u>x e r a t$, priusquam in $A<$ siam $>a<d>$ conloquium transiret. quo Dardanos $e<t>$ Denseletas caesis hos $<$ tibus $>$, qui Macedoniam ve<xa $>$ bant, in deditionem recepit.

(Granii Liciniani Annales 35. 70-81)

Conicere potestis, si recordari volueritis quanta religione fuerit eadem specie ac forma signum illud quod ex Macedonia captum in Capitolio posuerat $<$ T. $>$ Flamininus. Etenim tria ferebantur in orbe terrarum signa Iovis Imperatoris uno in genere pulcherrime facta, unum illud Macedonicum quod in Capitolio vidimus, alterum in Ponti ore et angustiis, tertium quod Syracusis ante Verrem praetorem fuit. Illud Flamininus ita ex aede sua sustulit ut in Capitolio, boc est in terrestri domicilio Iovis poneret.

(M. T. Ciceronis In Verrem 2. 4.129)

At infestis prope signis inferuntur Galli in M. Fonteium et instant atque urgent summo cum studio, summa cum audacia. Video, iudices; sed multis et firmis praesidiis vobis adiutoribus isti immani atque intolerandae barbariae resistemus. Primum obicitur contra istorum impetus Macedonia, fidelis et amica populo Romano provincia; quae cum se ac suas urbis non solum consilio sed etiam manu M. Fontei conservatam esse dicat, ut ipsa per bunc a Thraecum adventu ac depopulatione defensa <est>, sic ab huius nunc capite Gallorum impetus terroresque depellit.

(M. T. Ciceronis Pro Fonteio 44-45)

Nam superiore parte legis quem ad modum Pompeium oppugnarent, a me indicati sunt; nunc iam se ipsi indicabunt. Iubent venire agros Attalensium atque Olympenorum quos populo Romano $<P$. S Servili, fortissimi viri, victoria adiunxit, deinde agros in Macedonia regios qui partim $T$. Flaminini, partim L. Pauli qui Persen vicit virtute parti sunt, deinde agrum 
optimum et fructuosissimum Corinthium qui L. Mummi imperio ac felicitate ad vectigalia populi Romani adiunctus est, post autem agros in Hispania apud Carthaginem novam duorum Scipionum eximia virtute possessos...

(M. T. Cicero De lege agraria 1.5)

Quis Platorem ex Orestide, quae pars Macedoniae libera est, hominem in illis locis clarum ac nobilem, legatum Thessalonicam ad nostrum, ut se ipse appellavit, 'imperatorem' venisse nescit? quem ille propter pecuniam, quam ab eo extorquere non poterat, in vincla coniecit, et medicum intromisit suum qui legato socio amico libero foedissime et crudelissime venas incideret.

(M. T. Ciceronis De haruspicum responso 35 )

Ad ipsas venio provincias; quarum Macedonia, quae erat antea munita plurimorum imperatorum non turribus sed tropaeis, quae multis victoriis erat iam diu triumphisque pacata, sic a barbaris, quibus est propter avaritiam pax erepta, vexatur ut Thessalonicenses positi in gremio imperi nostri relinquere oppidum et arcem munire cogantur, ut via illa nostra quae per Macedoniam est usque ad Hellespontum militaris non solum excursionibus barbarorum sit infesta, sed etiam castris Thraeciis distincta ac notata. Ita gentes eae quae, ut pace uterentur, vim argenti dederant praeclaro nostro imperatori, ut exhaustas domos replere possent, pro empta pace bellum nobis prope iustum intulerunt.

(M. T. Ciceronis De provinciis consularibus 4)

Atque hanc Macedoniam, domitis iam gentibus finitimis barbariaque compressa, pacatam ipsam per se et quietam, tenui praesidio atque exigua manu etiam sine imperio per legatos nomine ipso populi Romani tuebamur; quae nunc consulari imperio atque exercitu ita vexata est vix ut se possit diuturna pace recreare; cum interea quis vestrum boc non audivit, quis ignorat, Achaeos ingentem pecuniam pendere L. Pisoni quotannis, vectigal ac portorium Dyrrachinorum totum in buius unius 
quaestum esse conversum, urbem Byzantiorum vobis atque buic imperio fidelissimam hostilem in modum esse vexatam?

(M. T. Ciceronis De provinciis consularibus 5)

Quis umquam provinciam cum exercitu obtinuit qui nullas ad senatum litteras miserit? tantam vero provinciam cum tanto exercitu, Macedoniam praesertim, quam tantae barbarorum gentes attingunt ut semper Macedonicis imperatoribus idem fines provinciae fuerint qui gladiorum atque pilorum; ex qua aliquot praetorio imperio, consulari quidem nemo redit, qui incolumis fuerit, quin triumpharit!

(M. T. Ciceronis In Pisonem 38)

Denseletis, quae natio semper oboediens huic imperio etiam in illa omnium barbarorum defectione Macedoniam C. Sentio praetore tutata est, nefarium bellum et crudele intulisti, eisque cum fidelissimis sociis uti posses, hostibus uti acerrimis maluisti. Ita perpetuos defensores Macedoniae vexatores ac praedatores effecisti; vectigalia nostra perturbarunt, urbes ceperunt, vastarunt agros, socios nostros in servitutem abduxerunt, familias abripuerunt, pecus abegerunt, Thessalonicensis, cum <de> oppido desperassent, munire arcem coegerunt.

(M. T. Ciceronis In Pisonem 84)

Cum diversissima parte orbis terrarum Cn. Pompeium Caesar victor sequeretur compluresque adversarios in Illyricum propter Macedoniae propinquitatem se reliquiis ex fuga collectis contulisse audiret, litteras ad Gabinium mittit, uti cum legionibus tironum quae nuper erant conscriptae proficisceretur in Illyricum coniunctisque copis cum Q. Cornificio, siquod periculum provinciae inferretur depelleret; sin ea non magnis copiis tuta esse posset, in Macedoniam legiones adduceret. omnem enim illam partem regionemque vivo Cn. Pompeio bellum instauraturam esse credebat.

(Anon. Bellum Alexandrinum 42. 4) 
Ultima Lageae stirpis perituraque proles, degener incestae sceptris cessure sorori, cum tibi sacrato Macedon seruetur in antro et regum cineres extructo monte quiescant, cum Ptolemaeorum manes seriemque pudendam pyramides claudant indignaque Mausolea, litora Pompeium feriunt, truncusque uadosis buc illuc iactatur aquis. adeone molesta totum cura fuit socero seruare cadauer? hac Fortuna fide Magni tam prospera fata pertulit, hac illum summo de culmine rerum morte petit cladesque omnis exegit in uno saeua die quibus inmunes tot praestitit annos, Pompeiusque fuit qui numquam mixta uideret laeta malis, felix nullo turbante deorum et nullo parcente miser; semel inpulit illum dilata Fortuna manu. pulsatur harenis, carpitur in scopulis hausto per uolnera fluctu, ludibrium pelagi, nullaque manente figura una nota est Magno capitis iactura reuolsi.

(M. Annaei Lucani Bellum Civile 8. 692-711)

Legiones effecerat civium Romanorum viiii: $v$ ex Italia quas traduxerat; unam ex Cilicia veteranam, quam factam ex duabus gemellam appellabat; unam ex Creta et Macedonia ex veteranis militibus, qui dimissi a superioribus imperatoribus in his provinciis consederant; [...] praeterea magnum numerum ex Thessalia Boeotia Achaia Epiroque supplementi nomine in legiones distribuerat [...] ex quibus dc Gallos Deiotarus adduxerat, d Ariobarzanes ex Cappadocia; ad eundem numerum Cotus ex Thracia dederat et Sadalam filium miserat; ex Macedonia cc erant, quibus Rhascypolis praeerat, excellenti virtute; d ex Gabinianis Alexandria, Gallos Germanosque, quos ibi A. Gabinius praesidii causa apud regem Ptolomaeum reliquerat, Pompeius filius cum classe adduxerat; dccc ex 
servis suis pastorumque suorum <numero> coegerat; ccc Tarcondarius Castor et Domnilaus ex Gallograecia dederant-horum alter una venerat, alter filium miserat-; cc ex Syria a Commageno Antiocho, cui magna Pompeius praemia tribuit, missi erant, in his plerique hippotoxotae.

(C. Iulii Caesaris Bellum Civile 3. 4)

[Caesar] Domitium Calvinum cum legionibus duabus, xi et xii, et equitibus d in Macedoniam proficisci iussit; cuius provinciae ab ea parte, quae libera appellabatur, Menedemus, princeps earum regionum, missus legatus omnium suorum excellens studium profitebatur.

(C. Iulii Caesaris Bellum Civile 3. 34)

Eodemque tempore Domitius in Macedoniam venit; et cum ad eum frequentes civitatium legationes convenire coepissent, nuntiatum est adesse Scipionem cum legionibus, magna opinione et fama omnium; nam plerumque in novitate fama <rem> antecedit. hic nullo in loco Macedoniae moratus magno impetu tetendit ad Domitium, et cum ab eo milia passuum $x x$ afuisset, subito se ad Cassium Longinum in Thessaliam convertit. hoc adeo celeriter fecit ut simul adesse et venire nuntiaretur, et quo iter expeditius faceret, M. Favonium ad flumen Haliacmonem, quod Macedoniam a Thessalia dividit, cum cohortibus viii praesidio impedimentis legionum reliquit castellumque ibi muniri iussit.

(C. Iulii Caesaris Bellum Civile 3. 36)

Caesar omnibus rebus relictis persequendum sibi Pompeium existimavit, quascumque in partes se ex fuga recepisset, ne rursus copias comparare alias et bellum renovare posset, et quantumcumque itineris equitatu efficere poterat, cotidie progrediebatur legionemque unam minoribus itineribus subsequi iussit. erat edictum Pompei nomine Amphipoli propositum, uti omnes eius provinciae iuniores, Graeci civesque Romani, iurandi causa convenirent. sed utrum avertendae suspicionis causa 
Pompeius proposuisset, ut quam diutissime longioris fugae consilium occultaret, an novis dilectibus, si nemo premeret, Macedoniam tenere conaretur, existimari non poterat. ipse ad ancoram una nocte constitit et vocatis ad se Amphipoli hospitibus et pecunia ad necessarios sumptus conrogata cognitoque Caesaris adventu ex eo loco discessit et Mytilenas paucis diebus venit.

(C. Iulii Caesaris Bellum Civile 3. 102)

Dumque ea in Italia geruntur, acri atque prosperrimo bello Cassius Rhodum, rem immanis operis, ceperat, Brutus Lycios deuicerat, et inde in Macedoniam exercitus traiecerant, cum per omnia repugnans naturae suae Cassius etiam Bruti clementiam uinceret. Neque reperias quos aut pronior fortuna comitata sit aut ueluti fatigata maturius destituerit quam Brutum et Cassium.

Tum Caesar et Antonius traiecerunt exercitus in Macedoniam et apud urbem Philippos cum M. Bruto Cassioque acie concurrerunt. Cornu cui Brutus praeerat, impulsis hostibus, castra Caesaris cepit - nam ipse Caesar, etiamsi infirmissimus ualetudine erat, obibat munia ducis, oratus etiam ab Artorio medico ne in castris remaneret, manifesta denuntiatione quietis territo -, id autem in quo Cassius fuerat, fugatum ac male mulcatum, in altiora receperat loca.

(Vellei Paterculi Historia Romana 12. 69-70)

Caesaris deinde testamentum apertum est, quo C. Octauium, nepotem sororis suae Iuliae, adoptabat. De cuius origine, etiamsi praeuenit, et pauca dicenda sunt. Fuit C. Octauius, ut non patricia, ita admodum speciosa equestri genitus familia, grauis, sanctus, innocens, diues. Hic praetor inter nobilissimos uiros creatus primo loco, cum ei dignatio Iulia genitam Atiam conciliasset uxorem, ex eo honore sortitus Macedoniam appellatusque in ea imperator, decedens ad petitionem consulatus obit praetextato relicto filio.

(Vellei Paterculi Historia Romana 2. 59. 1-2) 


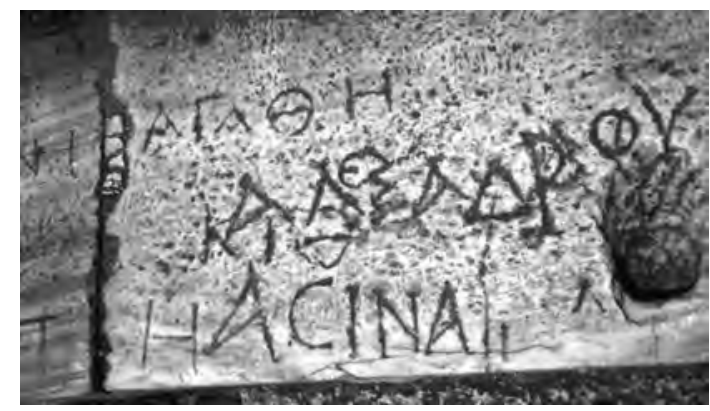

\section{Caesares Augusti Macedones adsimulant}

Prodigiorum loco habita sunt etiam, quae forte illo ipso die paulo prius acciderant. sacrificans respersus est phoenicopteri sanguine; et pantomimus Mnester tragoediam saltauit, quam olim Neoptolemus tragoedus ludis, quibus rex Macedonum Philippus occisus est, egerat; et cum in Laureolo mimo, in quo a[u]ctor proripiens se ruina sanguinem uomit, plures secundarum certatim experimentum artis darent, cruore scaena abundauit.

(C. Suetoni Tranquilli Vita Calligulae 58. 3-4)

Egressus vero pueritiam seu patris monit<i>s seu calliditate ingenii sive quod se Alexandro Magno Macedoni[ae] aequandum putabat, restrictior, gravior, vultu etiam truculentior factus est, prorsus ut eum, quem puerum scierant, multi esse non crederent. Alexandrum Magnum eiusque gesta in ore semper habuit. $T<i>$ berium et Syllam in conventu plerumque laudavit. Patris superbior fuit; fratrem magna eius humilitate despexit.

(Scriptorum Historiae Augustae Antoninus Caracallus 2. 1-3)

Iam vero ipsi milites iuvenem imperatorem sic amabant ut fratrem ut [de]filium ut parentem, vestiti honeste, calciati etiam ad decorem, armati nobiliter, equis etiam instructi et efippiis ac frenis decentibus, prorsus ut Romanam rem p. intellegerent, quicumque Alexandri vidisset exercitum. elaborabat denique, ut dignus illo nomine videret $<u r>$, immo 
ut Macedonem illum vinceret, dicebatque inter Romanum Alexandrum et Macedonem <m>ultum interesse debere. fecerat denique sibi argyroaspidas et chrysoaspidas, fecerat et falangem triginta milium hominum, quos falangarios vocari iusserat et cum quibus multum fecit in ter $<$ ra $>$ Perside; quae quid<e $>m$ erat ex sex legionibus similium armorum, stipendiorum vero post bellum Persicum maiorum.

(Scriptorum Historiae Augustae Antoninus Caracallus, 50. 5-5)

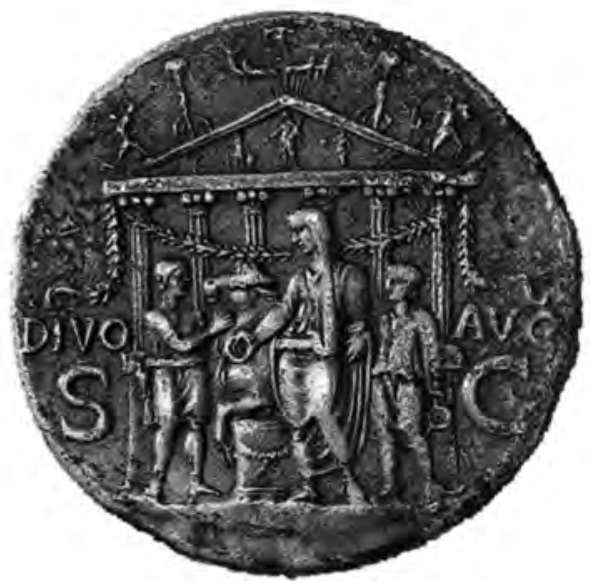

